\title{
Infancia en Indefensión (a)
}

\author{
Children in Defencelessness
}

Eduardo Bustelo Graffigna ${ }^{1}$

${ }^{1}$ Director Académico de la Maestría en Política y Planificación Social de la Facultad de Ciencias Políticas y Sociales de la Universidad Nacional de Cuyo. Argentina. mpps@fcp.uncu.edu.ar
RESUMEN El trabajo revisa las distintas concepciones sobre la infancia y la adolescencia que van desde la compasión, la inversión social, el rol de las ONGs y el emergente enfoque de derechos. Se plantean también los conflictos y tensiones en la difícil relación entre la infancia y la adolescencia y la representación democrática. El argumento central se basa en la visión de Michael Foucault en relación a que niños y niñas son víctimas de la biopolítica del control disciplinario o de la construcción de su subjetividad como sujetos "sujetados". El enfoque de derechos no escapa a su vez, de lo que Giorgio Agamben denomina "Estado de Excepción" en el que la ley incluye y excluye al mismo tiempo a quienes supuestamente debería defender. Siguiendo a Agamben surge el "Niño/a Sacer" como aquel que desde tiempos antiguos puede ser sacrificado o disciplinado y nadie puede ser condenado por esa situación. Para superar el estado de indefensión en que se encuentran niños, niñas y adolescentes se plantea una estrategia basada en un adecuado equilibrio entre autonomía y heteronomía en los procesos educativos y en una lucha política continua por la conquista de sus derechos.

PALABRAS CLAVE Defensa del Niño; Derechos Humanos; Controles Formales de la Sociedad; Controles Informales de la Sociedad; Formulación de Políticas.

ABSTRACT The work reviews the different ideological visions in relation to childhood and adolescence since the feeling of compassion, the concept of social investment, the role of NGOs and the emergent approach based on children's rights. The paper also deals with the tensions and conflicts between children and adolescents on one hand and the system of representative democracy on the other. The central argument all across the paper is based on Michael Foucault's approach on boys and girls as victims of the biopolitics of disciplinary control and since the adolescence, for the process of building up its subjectivity as "fastened subjects". In its turn, the approach based on childre$n$ 's rights can not surpass what Giorgio Agamben has called the "State of Emergency" in which the legal system includes and excludes those who are presupposed to be defended. Following Agamben's arguments, it seems to emerge the "Child Sacer" as the one that since old times can be sacrificed or drastically disciplined and nobody can be legally demanded for directly causing such a situation. In order to overcome the state of defencelessness it is argued that there is a need for a new strategy based on an adequate equilibrium between autonomy and heteronomy in all educational processes jointly with a continuous political fight to conquer children's rights.

KEY WORDS Child Advocacy; Human Rights; Social Control, Formal; Social Control, Informal; Policy Making. 
"En el principio es el grito. Nosotros gritamos. Cuando escribimos o cuando leemos, es fácil olvidar que en el principio no es el verbo sino el grito. Ante la mutilación de vidas humanas provocada por el capitalismo, un grito de tristeza, un grito de horror, un grito de rabia, un grito de rechazo: ¡NO!" John Holloway

\section{INTRODUCCIÓN}

Como todo campo (b), el de la infancia está compuesto por enfoques, análisis, estudios y conceptos; por la práctica que incluye un conjunto de acciones, programas y políticas; y finalmente, por una amplia gama de actores intervinientes. Aún siendo un campo que uno podría presumir "definido", es propenso a ambigüedades que ocultan relaciones sociales de dominación, lo que conduce a imprecisiones que uno podría afirmar que no son "inocentes". Esta aseveración tiene aún más fuerza dada la expansiva difusión mediática y la "preocupación" pública que el tema de la infancia cubre en la industria cultural.

En la dimensión temporal de la infancia y la adolescencia pueden reconocerse tres instituciones que dejan "marca" en su desarrollo: la familia, la escuela y los medios de comunicación. Las dos primeras son las que tradicionalmente han recibido más atención. En este trabajo, pretendo concentrarme -aunque no exclusivamente- en la forma más general e ideológica de trasmisión de las diferentes relaciones de dominación que se establecen sobre la infancia y la adolescencia. Allí sin duda tiene mucha incidencia la familia y todavía la escuela aunque, de una forma creciente, están asociados los medios de comunicación, que "amplifican" los discursos explícitamente distorsionados que pretenden ocultar esas relaciones de dominio. Intento avanzar en la localización y revelación de las "obscuridades" que considero más relevantes y en la envergadura que revisten las instituciones estatales en la protección de la infancia y la adolescencia como categoría social. Discuto asimismo el estatuto de los derechos de niños/as y adolescentes centralizando el campo de la infancia en el contexto de la lucha política. Por otro lado, recalco la importancia del Estado como un espacio público significativo en la lucha política por los derechos dadas las dificultades que la infancia y la adolescencia tienen para auto-representarse como actores en un escenario democrático. Desde estas dimensiones, procuraré explicitar los puntos más sobresalientes que determinan la producción de lo que en este campo denomino estado de indefensión en que se encuentran niños, niñas y adolescentes (c).

\section{LA BIOPOLÍTICA DE LA INFANCIA}

La infancia y la adolescencia son identificables con la vida como iniciación. La infancia es nacimiento y epifanía. El filósofo italiano Giorgio Agamben explica bien cómo los griegos no tenían una sola palabra sino dos para denotar la vida. Por un lado estaba la zoé que expresaba la vida pura, el simple hecho de vivir, la nuda vita (vida desnuda) como vida fuerza o vida biológica y por otro lado el bios, la vida relacional que implica el lenguaje, la política y la ciudadanía. En el caso de la infancia uno podría resumir la zoé en sobrevivencia y el bios en la ciudadanía y la política.

Foucault a su vez, ha planteado la palabra biopolítica para analizar la relación del poder con el cuerpo viviente y al mismo tiempo con la construcción de subjetividad. La biopolítica define el acceso a la vida y las formas de su permanencia y asegura que esa permanencia se desarrolle como una situación de dominación. En las instancias iniciales de la vida, la bipolítica designa la situación en donde la política suprime el bios para despojar todo lo humano de los humanos dejándolos sólo como zoé. Según Foucault, en la antigüedad el hombre tenía una existencia destinada a la vida política, en cambio esa relación se invierte en la actualidad en donde la política tiene como objeto al mismo ser viviente (1 p.173). Foucault, abandona así el enfoque clásico del poder jurídico institucional, para pasar a visualizarlo como el modo específico en que el poder penetra en el cuerpo mismo de las personas, en su subjetividad y en sus formas de vida. En un principio se trataba de un poder externo de castigo que generó la sociedad disciplinaria. Pero también Foucault llegó a conceptualizar el paso de una sociedad disciplinaria a una sociedad de control en donde los mecanismos y dispositivos 
de dominación se distribuyen y difunden más sutilmente en la sociedad logrando que cada vez más los ciudadanos internalicen las pautas y códigos adecuados de integración o exclusión. El poder se entreteje con dispositivos muy fuertes que organizan la vida y el cerebro humano a través de las poderosas máquinas de comunicación social, de las redes informáticas y de una amplia gama de sistemas de control. El poder se ejerce ahora desde adentro justo cuando muchos creen que desarrollan una subjetividad propia y autónoma. En otras palabras: el biopoder define las condiciones de ingreso en la fuerza laboral, las relaciones de "filialidad" en la familia, controla la individuación y la heteronomía en el proceso educativo, sistematiza su incersión en el mercado de consumo y regula su comportamiento a través de la ley.

La infancia es la instancia de la inauguración de la vida y en donde la aparición del biopoder aparece en su forma paroxística. $Y$ aquí distingo dos niveles. Uno es propiamente la vida sobreviviente, la zoé de niños y niñas que está relacionada a la materialidad del existir, a su mera sobrevivencia. Y lo que expresa esa situación es la infancia en situación de pobreza (d).

\section{LA POBREZA Y LOS NIÑOS, NIÑAS $Y$ ADOLESCENTES}

Muchos y variados son los conceptos de pobreza y sus dimensiones asociadas. La expansión teórica y metodológica que ha tenido el concepto es admirable y ha contribuido tanto a la concomitante confusión de sus usos y desarrollos programáticos, como a su incapacidad para inspirar una práctica trasformadora ante una realidad que, en el caso de niños/as y adolescentes, resulta intolerable (2-5).

Ahora bien, esta "producción" intelectual no es "cándida" y precisamente por ello, la mayor parte de ella tiene como objetivo ocultar aquello que "describe". Es que los discursos sobre la pobreza llevan embutidos los argumentos que derivan en acciones o modalidades de entender el problema que no son conducentes a su superación. Como afirmaré, existen en la biopolítica poderosos dispositivos ideológicos que proceden a legitimar una situación de dominación por medio de la ocultación de la relación social primaria que la expresa, que en este caso, es la de los ricos sobre los pobres. La pobreza de propuestas sobre la pobreza consiste principalmente en "empobrecer" su discurso focalizando el análisis sólo sobre los pobres ignorando la dominación de los ricos. Y es en esa tensión dominante-dominado en donde la situación de pobreza de la infancia debe ser entendida y localizada como relación social.

No pretendo aquí amplificar esta discusión con argumentos que he dado hace bastante tiempo (6). La pobreza y la riqueza no son sólo una distribución estadística. Esa relación tiene que ver principalmente con la igualdad, esto es con el entendimiento de que la pobreza se da al interior de relaciones sociales asimétricas asociadas en última instancia a la distribución del poder económico y a las modalidades en que éste influye y/o determina la práctica política. Para una política por y con la infancia, también el centro de la cuestión es el poder: esto es, si éste puede ser determinado en una dirección opuesta a la opresión que genera la pobreza y/o puede producirse un contrapoder que emancipe a las víctimas de su opresión. La cuestión de la infancia pobre es entonces una cuestión biopolítica mayor. No hay políticas para la infancia "fuera" de la política y que por lo tanto, no pasen por la construcción de relaciones sociales más simétricas. En otras palabras, todo discurso que plantee la pobreza por fuera de relaciones sociales de dominio y sobre todo, como una situación que requiere "soluciones" externas a la práctica política, concebida ésta como proceso colectivo emancipador, está asociado directa o indirectamente a ejercicios argumentativos para justificar el statu quo. O digámoslo sin eufemismos: analizar el hecho "social" del ser pobre o más particularmente, la situación niño/a-adolescente-pobre, no relacionándolos a los procesos económicos de concentración de ingresos, riqueza y poder, es como trabajar por y para su reproducción.

En el caso de los niños/as y adolescentes no hay más que una simple y transparente constatación: la mayoría de los niños son pobres y la mayoría de los pobres son niños. Uno de cada dos niños/as es pobre en el mundo. Ellos/as permanecen en el mundo de la zoé. La desigualdad 
de las relaciones sociales afecta profundamente la situación de la infancia (7). El análisis de los determinantes de la pobreza de los niños y niñas es por demás conocido. El impacto de sus consecuencias de todo orden están ya sobreargumentadas y nuestra responsabilidad como adultos es moralmente inconmensurable.

Pero siguiendo con mis argumentos, la cuestión no es sólo "analítica" sino sobre todo biopolítica pues hablamos de poder. Afirmo entonces que la cuestión central en la relación pobreza-infancia es el poder, puesto que niños/as y adolescentes son por autonomacia "los que no tienen poder". La biopolítica de la infancia consiste en mantenerla en la zoé como sólo sobrevivencia e inhibir o regular el desarrollo de la ciudadanía y su acceso a la política. Aún más, deseo enfatizar que la biopolítica implica la regulación de la vida pues en esta instancia de la edad temprana, es donde se define quién accede a ella, quién no y quién permanece en ella "reglamentando" las condiciones de esa permanencia. $Y$ esto es lo que trataré a continuación.

\section{TANATOPOLIITICA}

La biopolítica puede ser pensada como la capacidad regulatoria del poder sobre la vida pero también como "tanatopolítica" o sea, la negación de la vida o la política de expansión de la muerte. La mortandad de niños, niñas y adolescentes es la forma más "silenciada" de la tanatopolítica moderna. Denomino entonces forma superior de biopolítica a la que se "aplica" a las nuevas generaciones. En este caso, la muerte masiva y cotidiana de 30.000 niños/as y adolescentes por día, lo que aparece completamente "naturalizado" y nadie podría ser condenado por esta situación.

Es por esta razón que parangonando a Agamben (e) existe desde el inicio de la vida un "Niño Sacer" cuya muerte sagrada y ofrendada ha sido mostrada desde la antigüedad como gratitud o generosidad a los dioses. Desde el derecho romano, la vida del niño/a ha sido definida parodojalmente como contrapartida de un poder que puede eliminarla. Vitae necisque potestas designa ya en el hecho de "nacer" la potestas del padre de dar vida o muerte al hijo varón (9). También en un principio como explica Foucault, el soberano que convocaba a la guerra reclamaba la vida de sus súbditos: más que la vida exigía la muerte como el derecho de dejar de vivir. Esta situación adquiere hoy otras formas, como veremos, pero todavía persiste una forma tanática "moderna" que consiste en la naturalización del horror de millones de niños/as y adolescentes que mueren todos los años (10,6 millones) en el silencio, en una muerte verdaderamente "silenciada" y cuya responsabilidad sospechosamente, no puede ser atribuida a nadie.

Entran también como forma tanatopolítica, los niños/as y adolescentes que son reclutados para ir a la guerra, proceso de enrolamiento que comprende su instrucción para matar. En la última década más de 1,6 millones de niños han muerto en conflictos armados. Y el número de niños que han tenido que abandonar sus hogares debido a conflictos y violaciones de derechos humanos Ilega a más de 20 millones. Los mecanismos de inducción al odio, a la demonización del "otro" y la dinámica de intransigencia que se desata se asocian al extermino (f). En la dimensión de la muerte, el biopoder de los que dominan no tiene dudas: "se educa a poblaciones enteras para que se maten mutuamente en nombre de la necesidad que tienen de vivir"; y también Foucault lúcidamente expresa: "si el genocidio es por cierto el sueño de los poderes modernos, ello no se debe a un retorno, hoy, del viejo derecho de matar; se debe a que el poder reside y ejerce en el nivel de la vida, de la especie, de la raza y de los fenómenos masivos de población" (1 p.165,166).

Es un dato más que evidente que también los niños y las niñas son las primeras víctimas de la guerra. Desde 1990, se estima que el $90 \%$ de las muertes relacionadas a conflictos armados en todo el mundo han sido civiles y un $80 \%$ de las víctimas han sido mujeres y niños. En el lenguaje militar esto se denomina depravadamente "colateral damage" (g). Y a lo anterior deben añadirse las escuelas destruidas, los hospitales dañados, los insumos escolares y en salud básica inutilizados, y los sistemas de agua potable sin funcionar. 


\section{BIOPOLÍTICA Y SUBJETIVIDAD}

El segundo dispositivo de la biopolítica está relacionado propiamente al bios, esto es, los dispositivos destinados a la construcción de la subjetividad puesto que se trata de controlar la vida desde adentro mismo del sujeto. Es la sociedad de control de la que hablamos anteriormente. En el caso de la infancia y la adolescencia, esta construcción abarca tanto la visión de los adultos sobre los niños como la propia de los niños/as y adolescentes y su relación con los adultos y el mundo.

Deseo hacer aquí algunas precisiones conceptuales puesto que, en el caso de la infancia y la adolescencia, estamos muy lejos del "fin de las ideologías". Muy por el contrario, las comunicaciones distorsionadas forman parte de los mecanismos a través de los cuales el poder sobre niños/as y adolescentes legitima un sistema de dominación. Jürgen Habermas ha puntualizado que la ideología desactiva la forma comunicativa del lenguaje para servir a los intereses del poder. Y si las formas de comunicación son sistemáticamente distorsionadas se producen dos cuestiones cruciales para entender su vigencia en la lucha política: la apariencia de normatividad y la imparcialidad. La normatividad hace alusión a un "deber ser" cuyo "deber" se impone como práctica discursiva de poder. En el caso de la infancia y la adolescencia es un "deber" despótico al que todo "se debe". Es un deber, sin apelativos, a los adultos. La imparcialidad a su vez se refiere a su supuesto carácter "objetivo": coincidencia "pura" y plena con una "realidad" ante la cual sólo cabe someterse. En esas condiciones, la distorsión sistemática de mensajes consigue abolir incluso las propias dimensiones a través de las cuales puede juzgarse su "deformación" y de ese modo volverse invulnerable a la crítica. La ideología que puede ser expresada en la forma de un discurso, de una política o de un programa alcanza así su máxima potencia al invalidar su exterioridad. Como lo ha explicado Terry Eagleton, la ideología llega a su punto máximo de eficacia cuando niega la posibilidad de un "afuera" (h).

Pero la ideología también está relacionada al sujeto pues penetra en el desarrollo mismo de la subjetividad: es una estructura que se impone sin pasar necesariamente por la conciencia (i). Es por esto que Bourdieu piensa en el concepto de habitus $(10$ p.129,130) con lo que designa la inculcación en hombres y mujeres de un conjunto de disposiciones duraderas que generan lo que domina "inconciente cultural". Se "naturaliza" así un orden social por medio de estructuras objetivas y subjetivas. Particularmente agudas son sus observaciones de cómo opera una ideología en términos de "campos" (10 p.49). Éstos son sistemas de relaciones sociales que funcionan respecto a un área en donde se compite por lo mismo y que funcionan con su propia lógica interna. En los campos y particularmente en el de la infancia, se juega el máximo de dominio cuando los agentes que detentan el poder se legitiman con un discurso distorsionado que otorga "legitimidad" a los participantes dóciles y al mismo tiempo, consiguen dejar de ser reconocidos como lo que son: esto es, poder y dominación.

En el campo de la infancia, estas prácticas discursivas distorsionadas y manipulatorias se han constituido en un orden "natural" en donde los factores de poder conocen que es en el "tiempo" de la infancia donde se inicia el proceso constructivo de su situación de dominio y en donde el ocultamiento de la relación de domino se hace más evanescente. Como afirmé, se cumple en este campo como quizás en ningún otro, aquel primado que establece que una relación de dominación para ser efectiva debe permanecer oculta.

Funciona así como una inmensa máquina de captación de incautos o de "lavar" conciencias o como un "analgésico" de amplio espectro para aquellos que sinceramente se comprometen y creen hacer "el" bien.

Pero también en el campo de la infancia existen rivalidades y luchas para obtener poder simbólico y prestigio entre diferentes grupos, organismos civiles, religiosos, sindicales, organizaciones sectoriales y empresas comerciales. Lo anterior implica que al interior del campo como manifiesta Foucault, existe una microfísica del poder y analizarla sería como descubrir la anatomía del mismo. "Se trataría en él del cuerpo político como conjunto de los elementos materiales y las técnicas que sirven de armas, de relevos, de vías de comunicación y de puntos de apoyo a las relaciones de poder y de saber que 
Figura 1. SILLA ELÉCTRICA PARA QUE "JUEGUEN" LOS NIÑOS.

En un shoping de la ciudad de Rosario en Argentina (que puede significar "muchos lugares en el mundo"), se instaló en un patio de juegos infantiles una silla eléctrica para que "jueguen" los niños. La silla era una emulación de la que se utiliza para ejecutar a los condenados a muerte. Se manejan microvoltages para "recrear" la horrorosa situación previa a la instancia final que clausura la vida.

El empresario que la insta-

ló, declaró que era como cualquier juego; que él "no veía" la diferencia con otros "entretenimientos" infantiles y que los padres traían a los hijos "libremente" para que jueguen con este instrumento macabro. Esta situación tiene muchos ángulos para reflexionar que son apropiados a los puntos que trato en este trabajo.

La silla puede ser tomada como la metáfora tradicional del castigo biopolítico definitivo que aguarda a la infancia si no se siguen las normas aceptadas. La vida sagrada puede ser dada y puede ser quitada y el "matarás" forma parte de la ley desde la infancia temprana.

A su vez, la silla puede ser tomada como la simbolización del orden disciplinario del que representa la instancia final máxima mostrada a los niños como "juego". El

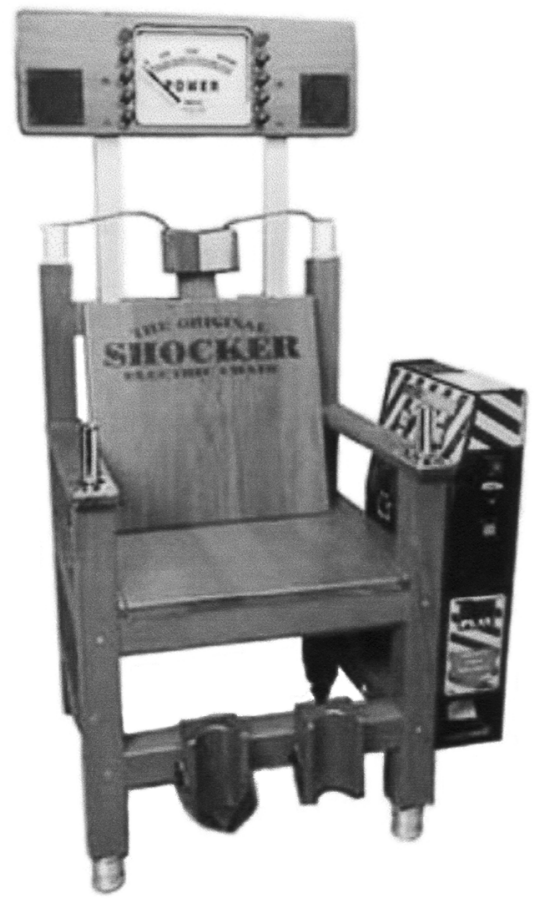
mensaje se naturaliza pues el empresario no "ve la diferencia" ni tampoco los padres parecen captar el mensaje implícito de la "ley" que le espera a sus hijos. El instrumento se ofrece al entretenimiento con toda su "inocencia".

Como lo ha expresado Foucault en Vigilar y Castigar "se trata de reincorporar las técnicas punitivas -bien se apoderen del cuerpo en el ritual de los suplicios, bien se dirijan al alma- a la historia de ese cuerpo político". Y sugería que las prácticas penales sean consideradas menos como una consecuencia de la teorías jurídicas que como un capítulo de la anatomía de la política. La silla en su carácter "inofensivo" e "inocente" es una ilustración del Estado de Indefensión: todos podemos defender los "derechos" de los niños/as pero al final, la metáfora "electrizante" nos enseña que ni la tortura, ni el sufrimiento y la muerte podrían ser descartados en el proyecto de una humanidad inconclusa. 
cercan los cuerpos humanos y los dominan haciendo de ellos unos objetos del saber" (11 p.35).

Ampliando, podemos afirmar que el poder que se ejerce en este campo, más que una propiedad o un atributo, es una estrategia de dominación y está compuesto de tácticas, subterfugios, tergiversaciones conceptuales, manipulaciones y de dispositivos que se aplican no como una prohibición a quienes están "adentro" del campo "sino que los invade, pasa por ellos y a través de ellos; se apoya en ellos..." para lograr en el caso de la infancia y la adolescencia sujetos obedientes, sumisos y ordenados (Figura 1).

Hechas estas reflexiones, veamos ahora con más detenimiento los dos enfoques que considero hegemónicos respecto a la relación social que involucra a niños/as y adolescentes. Digamos desde el inicio, que ambos no son excluyentes sino funcionalmente complementarios.

\section{LA COMPASIÓN}

El primer enfoque prevaleciente respecto de los niños es ciertamente el basado en la compasión. Siendo seres indefensos e inocentes son moralmente no imputables. Entonces: ¿cómo no movilizar los sentimientos, cómo no ayudar, cómo no entregarse a su "causa", cómo no asemejarse a los niños/as? Los medios de comunicación masiva abusan en la presentación de este discurso mediante la promoción de situaciones de ayuda social "meritoria" y personas "ejemplares" con avisos y campañas publicitarias. También se apela a temas que crean escenarios de expectación perversa mostrando situaciones y casos límite de abuso, trata y explotación de niños/as y adolescentes. Esta "exageración" está intencionalmente presentada más allá de la situación "objetiva" de esos niños/as oprimidos puesto que se "produce" este ambiente mediáticamente exasperante con el propósito principal de vender espacios publicitarios. Igualmente, esta estimulación se presume que está directamente asociada a la sensibilización de la población que es la base de la construcción de un contexto "compasivo" (Figura 2).

Aunque se apela al niño/a pobre, lo fascinante es como se evade el problema de la redistribución de los ingresos y la riqueza que es la "base" de la explicación de la infancia pobre: se plantea que lo que les sobra a unos es exactamente lo que necesitan otros y que por lo tanto, sería sólo suficiente poner en contacto al donante y al necesitado. Dar lo que "sobra" implica además soslayar la relación de dominación en que se hallan inmersos los niños/as pobres pretendiendo que hay una solución que se deriva, por un lado, de un compromiso individual al que se le atribuye la solidaridad (benefactor) y por el otro lado, a la aceptación pasiva de una "generosidad" que anularía la dominación.

Asimismo, dicha "generosidad" coincidiría con el atributo de ser gratuita ya que, eliminar la pobreza depende sólo de un gesto, apenas una actitud que en el fondo "no cuesta nada" (j). El supuesto "no costo" a su vez está pensado por un lado, como contrapartida a lo "costoso" y corrupto de las políticas estatales y, por otro lado, al voluntariado social al que se le asocian las características de seriedad, generosidad y altruismo (k).

Digamos que los sentimientos son imprescindibles pero ciertamente no suficientes. Una cosa es "con-padecer" y otra es esparcir gas lacrimógeno para neutralizar una conducta proactiva por una efectiva implementación de los derechos de la infancia. Asimismo afirmo que el paternalismo/maternalismo reproduce una relación "protectora" descaradamente asimétrica. El que protege, es dueño del poder y la voluntad sobre "el desprotegido". Además, no es una relación que "hace" el bien o que busca hacer el bien en el otro sino principalmente que "me hace bien" en el sentido de una actitud narcísica (I). No provoca creciente autonomía como fuente para la expansión de una subjetividad responsable, origen de ciudadanía. Y fundamentalmente, porque el problema no es de índole particular y no se resuelve desde un compromiso personal con un niño o un proyecto, sino en un espacio colectivo construido como política pública. La dependencia y la cautividad de los niños de una relación de "padrinazgo" los hace víctimas del despotismo de la benevolencia (m). Y cuando con este enfoque se responde con programas del sector público, se promueve una ciudadanía "tutelada" que termina bajo los argumentos del amparo, en la criminalización, opresión y represión de los niños, niñas y adolescentes. 
Figura 2. EL "BUEN" SAMARITANO.

La publicidad social de las organizaciones sociales del stablishment, del Banco Mundial y más particularmente de las empresas con "responsabilidad" social, usa a personas ejemplares y a su compromiso con niños/as y adolescentes. Pero mediante este artilugio se "invierte" la significación de ejemplaridad y se pretende "demostrar" un camino cuyo sentido invoca en primer lugar, que los temas asociados a la lucha contra la pobreza y la igualdad son un compromiso personal y que nada tienen que ver con la emancipación de relaciones sociales de dominación y por tanto, con la política. Lo "personal", a su vez, quiere decir una disposición interna en donde "hacer el bien" coincide con "el propio" bien: se trata de una "solidaridad" egoística. Y además, socialmente "no cuesta nada": se trata solamente de "dar una mano". En segundo lugar, en esta lucha nada tiene que ver lo públicoestatal sino que implicaría simplemente un compromiso que queda encapsulado en el ámbito privado. Y cuánto mejor si ese compromiso es "voluntario"; esto es, enraizado en las actitudes cotidianas de todas las personas durante todos los días. ¡Así de simple!

En tercer lugar, la "amoralidad" de la publicidad disfraza una inten-

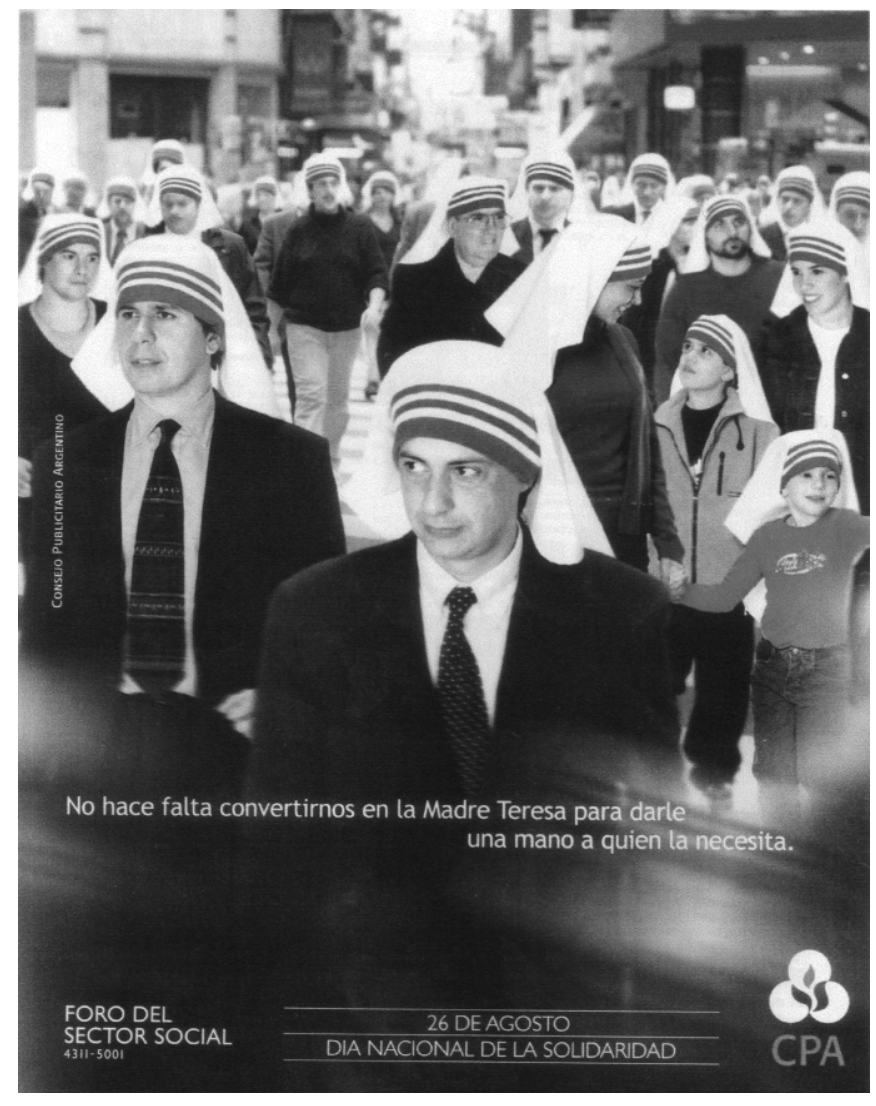
ción legitimadora que busca hacer aparecer como idénticos la "bondad" del capital y las organizaciones sociales que lo representan, con el compromiso respetable y sincero de una mujer con la causa de los niños/as y adolescentes. Este testimonio personal podría por supuesto ser cuestionado, pero en ningún caso banalizado.

Fuente: Elaborada en base a una publicidad aparecida en múltiples medios de comunicación nacionales y provinciales (12). 
El enfoque "compasivo" tiene además -en su evocación de una supuesta "responsabilidad social"- una práctica recaudatoria. En realidad se promueve la sensibilización presentando situaciones límite, en donde movilizar sentimientos, tiene también como objetivo promover donaciones (pecuniarias, en bienes o en tiempo del "donante"). Y la donación da "prestigio". Más perversa y tergiversada en su fingida intencionalidad es la organización de shows benéficos, rifas o "cenas" recaudatorias en donde los dueños del poder además de disfrutar y "pasar un buen momento" recaudan dinero para los niños y niñas pobres (n). La crónica mediática es explícita en presentar una riqueza obscena como espectáculo que "divierte para beneficiar" a los niños. En este sentido, el discurso no tiene ninguna pretensión de distorsión comunicativa: los niños/as son un motivo más para mostrar la riqueza y la pertenencia a los círculos distintivos del poder.

El problema comienza cuando el niño/a entra en "conflicto con la ley". Allí es donde naufraga este enfoque ya que "convierte" la compasión en feroz represión: el poder termina sin piedad imponiéndose a los que no tienen poder. El despotismo se hace explícito pues el "niño-amenaza" debe ser sometido y a estos afectos, considerado "adulto". En el momento de la "internación", que coincide con la abolición efectiva de la voz y la libertad del sujeto, es cuando se hace concreta "la verdadera" responsabilidad de una subjetividad que ahora se considera "autónoma y plenamente responsable". La relación se "invierte": de "protegido" se pasa a ser responsable y los "protectores" se convierten así en la fuente de la desprotección más inhumana.

La soberanía de esta relación de dominio termina finalmente expresándose en el poder de policía. No sólo en la institución policial, sino también en los mecanismos de control y de poder que aseguran el "disciplinamiento" de la infancia y la adolescencia. Los niños/as y adolescentes terminan conformando lo que Robert Castel denomina "clases peligrosas". De este modo, puede percibirse en muchos países respecto a la infancia y la adolescencia, un paulatino deslizamiento de un Estado Social a un Estado de la Seguridad en donde se proclama sin eufemismos la "tolerancia cero".

\section{LA "INVERSIÓN"}

El segundo enfoque prevaleciente es el de la infancia y la adolescencia como inversión económica que produce una determinada rentabilidad. Se trata de una colonización conceptual del lenguaje expansivo de la economía profusamente propagada por los bancos internacionales. Ésta es la versión utilitarista e individualista más pérfida: es conveniente en términos económicos "invertir en capital "humano", una paradoja para la más inhumana de todas las lógicas opresivas: la lógica del capital que ahora se hace "humana". Educar a un niño me conviene y nos conviene aunque no sabemos si a ellos "les conviene" puesto que no conocemos de qué "educación" se trata. Y esta conveniencia, es una conveniencia económica que en términos monetarios se mide como "tasa de retorno". Con este argumento, que implica la introducción de la razón utilitaria por sobre los derechos, se pretende convencer al poder (los bancos codiciosos, los empresarios corruptos y los gobernantes ineptos) que los niños son buenos para la lógica de la ganancia. Así tenemos hoy los bancos y las grandes corporaciones "trabajando" y haciendo promociones por los niños/as. Mercantilización de la infancia es así negocio para las ahora "buenas" empresas y los bancos que mejoran así su "imagen" institucional (o).

Igualmente, la lógica de la ganancia argumenta que la inversión en educación determina a mediano plazo el crecimiento económico y que éste a su vez, derrama generosa y equitativamente sus beneficios. Y si esto no alcanza a los niños/as para ello existen "redes de seguridad" o "redes de contención" o "solidaridad privatizada", un eufemismo para calificar el camino de la no inclusión. O el voluntariado como una modalidad para expresar inescrupulosamente el carácter gratuito de los servicios de bienestar infantil.

De nuevo, el problema "realmente" aparece cuando los niños/as y adolescentes se salen del "guión" y entonces el enfoque los convierte rápidamente en "costos"; son costos ahora sí en seguridad que la sociedad tiene que pagar. Sólo cuando el niño/a se hace "delincuente" se convierte en un problema o preocupación pública. Los temas inversión y seguridad están íntimamente conectados en la lógica de esta 
argumentación ya que, la "supuesta" inversión significaría en realidad el pago por la seguridad de no ser agredidos por los niños y adolescentes en un próximo futuro.

En otras palabras: la versión "soft" de este enfoque afirma que la inversión en la infancia se conecta con la posibilidad de crecimiento vía el aumento de la productividad que se desprende de mayores niveles de educación. Éste sería además el único camino admitido de la inclusión y la movilidad social. En la versión "hard", sorpresivamente "la inversión se invierte" presentando la infancia desde el miedo o la amenaza potencial ya que, si no se "invierte" en la infancia, ellos terminarán en una situación de "incontención" o desborde, lo que será un atentado a mediano plazo a la propia seguridad individual. Además, no "invertir" ahora significa incurrir a mediano plazo en costos mayores para toda la sociedad. En ambos casos, la conclusión es predecible: los niños/as y adolescentes terminan en la ferocidad de la represión de sus derechos.

Antecedentes de esta actitud pueden ser encontradas en el movimiento "salvadores del niño" en EE.UU. en el siglo XIX descriptas en el excelente y pionero trabajo de Anthony Platt. El término "salvadores del niño" se ha utilizado para denominar a un grupo de "reformadores sociales desinteresados que veían su causa como caso de conciencia y moral y no favorecían a ninguna clase ni ningún interés político particular". Se definían como altruistas y humanitarios y "su interés en la pureza, la salvación, la inocencia, la corrupción y la protección reflejaba una fe firme en la rectitud de su misión" (17 p.31). Sin embargo, ellos fueron los precursores de la asociación del niño con la criminalidad y de tratarlos como un grupo social diferente y peligroso, y en su actuar, siempre terminaron imponiendo "sus concepciones de clase y elitistas". El mencionado estudio concluye que dicho movimiento nunca fue una empresa humanitaria para ayudar a los obreros y los niños pobres a liberarse del orden establecido que los oprimía sino que se trataba de personas pertenecientes a las clases media alta y alta que contribuyeron a crear nuevas formas de control social para proteger su poderío y defender sus privilegios (p). Los "salvadores del niño" fueron los que terminaron "justificando" la delincuencia.
Pero lo que es realmente una paradoja entre tantas en este campo es que, la distorsión comunicativa pretende hacer "actuar" a los detentores del poder y el stablishment económico (los bancos; las grandes empresas; las compañías multimedios; etc) en favor de la infancia bajo la idea de "responsabilidad social". Todos tienen que hacer algo y forma parte de los "nuevos" enfoques del management que estimulan la vida ejemplar de los CEOs (Chief Executive Officer) a dedicar tiempo, esfuerzo y contribuciones económicas para ayudar a la infancia. El capital y su ética asociada de ganancia sin límites se esfuerza por legitimarse como "responsable", lo que lo desculpabilizaría de su responsabilidad "social" efectiva que es pagar impuestos y cumplir con sus deberes en el financiamiento y acompañamiento de una política pública. Aparece como "benévolo" disimulando su rapacidad insaciable y al presentarse como "generoso" encubre las bases materiales objetivas en donde basa su poder opresivo (Cuadro 3).

\section{LA INFANCIA Y LOS DERECHOS}

Considero ahora la principal fuente legitimadora de la protección de la infancia que es la Convención Internacional de los Derechos del Niño (CIDN). Éste es el instrumento político y jurídico más importante que supuestamente regula el campo de la infancia y la adolescencia. Ha sido Ilamada "la primera" ley de la humanidad ya que es el tratado internacional que más ratificaciones ha tenido a lo largo de la historia (q). Su relevancia pedagógica ha sido y es fundamental como lo explica Gómes da Costa (18). Su importancia política, jurídica y programática es incuestionable. Sus debilidades también.

La CIDN corresponde a un momento del desarrollo de la categoría infancia en donde su objetivo es constituir al "niño" como "sujeto de derechos": derechos que serían emulables a los de los adultos. Ahora, este proceso no es tan simple y puede ser visualizado desde ángulos muy diferentes.

Así por un lado, hay una "visión" que promueve un concepto de infancia en donde ésta se aproxima a la idea de una completa autonomía 
Una nueva forma de legitimación del capitalismo pareciera que pasa por presentar la emergencia de un moderno empresariado preocupado con los temas sociales. Esa "preocupación" mostraría un compromiso real con la sociedad y sus problemas.

Aunque continúan haciendo la clásica filantropía, los empresarios contratan ahora profesionales y "arman" equipos que estudian y proponen soluciones concretas para los problemas sociales desde un punto de vista "objetivo". Aparecen así jóvenes profesionales, preferentemente de apariencia atléticodeportiva, y empresarios "innovadores" ahora también "voluntarios" de acciones sociales. Modernos ejecutivos especializados (CEOs) en "gerencia social" y preparados para transformar un aparato público anquilosado y carente de transparencia con las novedosas técnicas "objetivas y eficientes" de la gestión privada.

Pero nada de lo anterior está exento de la intención expresa de construcción de poder y de dominio, sea comercial o político. Así no se puede ignorar la creciente aparición de "empresarios" (eufemismo para decir "hombres/mujeres de negocios", muchos de ellos sin empresas) que se hacen ahora "visibles" en la política, ni mucho menos, operativos de "social marketing" para hacer un verdadero "lifting" de las empresas presentándolas ahora con un "rostro" bueno y socialmente comprometido. En este contexto, es significativo recordar que paradojalmente, fue un empresario quien primero estudió y midió la pobreza. Su nombre fue Charles Booth y perteneció a la tercera generación de una familia de exportadores de Liverpool. Fundó la compañía naviera The Booth Steamship Company con la que fue tremendamente exitoso.

Simultáneamente a su actividad empresaria, Booth emprendió un estudio en donde por primera vez se midió la pobreza y que concluyó en un libro publicado en 1902: La Vida y el Trabajo de la Gente de la Ciudad de Londres que comprendió 17 volúmenes. Se le atribuye haber inventado el concepto "línea de pobreza" metáfora que tomó observando los barcos de su firma: la línea que marcaba en el casco de la nave, el nivel de sumersión de la misma. Pero Booth pensaba que la pobreza no era sólo la cuestión de su medición y estudio.

Su compromiso social no era algo que practicaba "afuera" de su empresa sino que comenzaba con la misma. En tiempos en que casi no existía ninguna legislación laboral, Booth estableció un plan de pensiones para los empleados de su firma; un plan para compartir las ganancias de la compañía y bonos anuales que se daba a los trabajadores, especialmente en los períodos de recesión para incentivar la productividad. Esos bonos, pagaban una alta tasa de interés y se acreditaban cuando el trabajador se jubilaba. Booth se adelantó por varios años en la idea de que la ética empresarial era sobre todo una responsabilidad social y pública.

Tampoco su compromiso social era una cuestión meramente empresaria sino también, una ética personal. Así Booth calculó que le hacia falta para vivir -tanto a él como a su familia- 1.000 libras por mes en tanto que ganaba 2.000. Analizó que gastaba en alimentación 150 libras pero como creía que los trabajadores estaban mal pagos por lo menos en un 50\%, consideraba que tenía que "devolver" de algún modo 75 libras. Igualmente, examinando otros rubros de su consumo familiar encontró un "excedente de explotación" equivalente a 500 libras que entregaba a los que necesitaban, simplemente "para que la humanidad volviese a ser lo que tenía que ser".

El estudio que realizó sobre la pobreza y del cual él mismo escribió 8 volúmenes, demoró 17 años pero no por ello abandonó sus actividades empresariales: escribía a la noche, en los fines de semana, durante sus viajes a Europa continental y EE.UU. Tampoco pagaba a otros para que levantasen los datos de su estudio. Aunque tenía ayudantes, él mismo convivía en la casa de las familias pobres estudiando su vida y sus hábitos. Llegaba a pasar semanas completas viviendo en los barrios más pobres de la ciudad de Londres. Presentando los resultados de su trabajo cuantitativo y cualitativo en la Real Academia Estadística de Londres afirmó que "en la vivencia con los pobres... y no en la estadística, radica el poder de cambiar el mundo".

Booth no organizó ninguna Fundación para su empresa, ni financió museos artísticos para que los visiten los ricos, ni aceptó subsidios públicos, ni pidió exenciones impositivas por las actividades que realizaba. Fue un simple practicante del concepto de "empresa ciudadana" que implicaba tanto titularidad de derechos como de obligaciones. Pensaba que la responsabilidad social de la empresa no consistía en una "ética post-ganancia" ni en una "façade" para mejorar sus ventas ni mucho menos, en la construcción de un espacio público para el prestigio personal o para conquistar poder político.

Fuente: Elaboración en base a Poverty and Compassion de Gertrude Himmelfard (19). 
despojándose de la heteronomía que la "domestica" a través de la familia o la "socializa" mediante la escuela. El niño/a de acuerdo a su edad, adquiere progresivamente derechos, y en la medida que accede a su subjetividad, conquista su plena autonomía. El punto final de ese viaje sería un mundo en el cual el niño es visto como un continuo $y$ no introduce ninguna fractura generacional: la niñez es un tiempo de preparación para la adultez para repetir "la adultez" de los adultos.

Por otro lado y en una visión opuesta, el niño es visualizado también como un ser en evolución pero esa evolución culminaría en un proceso autónomo que se define por su diferencia y oposición al mundo de los adultos y más particularmente, su emancipación, esto es: la construcción de su subjetividad consistiría en superar el mundo adulto, de manera que se trata de un proceso que se hace discreto y discontinuo.

El primer camino, describe tal vez una posibilidad idealizada pero bien próxima a la imagen de la infancia "neoliberal" que cuenta la historia de niños y niñas que se encaminan con certeza hacia un destino marcado por el consumo y la competencia en donde se asegura el triunfo de los "más aptos". Aquí lo más importante es el acceso a la libertad y los derechos individuales. No existe la infancia, existen niños/as individualizados cada vez más tempranamente. La igualdad que implica la sustentación de una relación simétrica con otros, es sólo considerada como igualdad de oportunidades. El niño/a es un adulto "menor".

En la segunda visión, en cambio, se sigue sosteniendo una subjetividad individual desde que no se promueven las instancias institucionales heterónomas que colocan al niño/a en su relación e ingreso a la sociedad: se trata de un niño/a, esta vez distinto del adulto, pero su evolución hacia la adultez termina en una especie de "alternativismo individualista". Se plantea una fractura sólo intergeneracional y en consecuencia, se produce una individualidad "sin sociedad".

Ahora bien, en medio de las dos versiones descriptas, corre una tercera visión, en donde la autonomía y la heteronomía son definidos como dimensiones constitutivas en tensión continua. Pero en este proceso, los elementos heterónomos que sitúan al niño/a y al adolescente como parte de una sociedad y de su historia no son una imposición, sino un diálogo entre la generación adulta y la generación más joven sobre cómo construir y direccionar el proceso emancipatorio ya que ambas, son igualmente categorías histórico-sociales que en el caso de la pobreza, quedan del lado de las víctimas. Si bien hay una tensión insalvable entre el adulto y la infancia, la principal contradicción radica en este caso, en que ambas categorías se corresponden en una relación social en donde ambas son oprimidas.

Prosiguiendo con esta reflexión deseo introducir ahora una definición que considero crucial: todos los derechos de los niños/as y adolescentes son derechos "sociales" en el sentido de que su garantía es esencialmente política y por lo tanto, corresponde a la sociedad en su conjunto implementar. No son esencialmente derechos subjetivos puesto que no se corresponden con derechos civiles individualizados. Ellos existen y por supuesto no deberían ser dejados de lado. Pero los derechos definidos en la CIDN deben ser considerados como derechos "sociales" en el sentido que corresponden al ámbito de lo público y al de una categoría social. Defino a la infancia y la adolescencia como categoría social al valor y ubicación relativa que se da a ese período del desarrollo humano en la cultura. En este contexto, son derechos que una generación busca fundar en una nueva generación emergente como parte de un proceso emancipatorio. $\mathrm{Y}$ al definirlos como sociales, trato asimismo de resituar esos derechos en el más alto posicionamiento ético de la cultura. En este sentido, los derechos de la infancia y la adolescencia se corresponden con una responsabilidad indeclinable de los adultos y a esto Ilamo "eleidad": hacernos cargo definitivamente de "ellos". La "eleidad" de los niños/as y adolescentes demanda una responsabilidad sin amenazar con un castigo y más allá de prometer una recompensa. Es esa fragilidad que revela nuestra capacidad de actuar moralmente como pura responsabilidad sin esperar nada de ellos. Como afirma ciertamente Bauman (20 p.99,107), la responsabilidad hacia los niños/as puede ser pensada como la ética de una caricia: "la mano que acaricia siempre se mantiene abierta, nunca se cierra para asir", jamás demanda posesión. Y éste es el sentido más profundo de lo que Ilamamos "derechos". 
Lo anterior tiene una significación sustantiva en el ámbito de una tensión estructural en el desarrollo de la infancia; esto es el eje autonomía-heteronomía. Como afirmé, el niño/a en su desarrollo no parte de una subjetividad pre-constituida pero evoluciona en búsqueda de su autonomía y en lo que los psicólogos denominan "identidad". La visión liberal considera que es en el período de la infancia y la adolescencia donde se van constituyendo los derechos como parte de la construcción del individuo y que, estos derechos serán "individuales" llegados a su fase "adulta". En este sentido no hay derechos "sociales" atribuibles a la infancia y la adolescencia. Por otro lado, sostengo que los derechos de la infancia deben ser garantizados por toda la sociedad y por lo tanto, son derechos heterónomos. En otras palabras, se trata de derechos transindividuales que relacionan una autonomía en desarroIlo que simultáneamente está relacionada con un ser parte de una sociedad, de su historia y de los dilemas en la representación de su futuro. Y deliberar sobre el futuro de una sociedad es nada menos que discutir la infancia y la adolescencia hoy. Entonces, como no son derechos individuales, los derechos de niños/as y adolescentes son los derechos de "ellos", de aquellos que están más allá de mí, de aquellos que me sobrevivirán. Por eso son derechos relacionados a la "otredad" o sea, de una "otredad" que se niega a volver sobre el "yo" retrotrayéndose a lo mismo. Son "otros" más allá del nos-otros. Los derechos de la infancia y la adolescencia corresponden en realidad a la "eleidad", a ellos y por lo tanto, son pura negación de nuestra "mismidad", pura generosidad sin esperar reciprocidad. Son derechos fuera del "cálculo" sobre todo del cálculo utilitarista de lo que me conviene (r) $(21,22)$.

Hechas estas consideraciones cruciales cuyas implicancias son decisivas en cómo analizo la CIDN, deseo recordar algunos puntos decisivos en su desarrollo para contextualizar y calibrar su importancia y luego, tratar la cuestión no menor de su status jurídico (s). Es importante aquí levantar al menos cuatro puntos que son imprescindibles recordar.

En primer lugar, habría que hacer un análisis de las "reservas" que los países hicieron a la Convención (t) en el momento de su ratificación pues nos encontraríamos seguramente con sugerentes sorpresas. La Convención ciertamente está desde su génesis siendo negada en importantes cuestiones relacionadas a la vida misma y en esto también opera la biopolítica de los niños. No sabemos pues con precisión cuánto de su corpus sustantivo está "universalmente" vigente (u). Recordemos a su vez en segundo lugar, la discusión que se planteó respecto al "interés superior del niño" cuando se discutió la CIDN (24). Es importante aclarar desde el inicio, que la CIDN en su artículo 3 inciso 1 habla del "mejor interés del niño" (the best interest of the child) y no del interés "superior" del niño (v). En su versión original, la propuesta consistía en el interés "superior" del niño (the paramount interest) pero varios países se opusieron y la versión final estableció definitivamente "el mejor" interés del niño. Cambio fenomenal que introdujo un relativismo insuperable que trasunta un espíritu paternalista pues: ¿quién define ahora qué es lo "mejor" para los niños? ¿Son los padres? ¿Es el Estado? ¿Son los códigos sociales que se han desarrollado históricamente y conforman un hábito socialmente establecido? Se dejó una verdadera y lamentable aporía.

Es también importante aclarar siguiendo a Alston y Gilmour-Walsh (24 p.20-25) que según el artículo 3 de la CIDN, al interés superior del niño se le debe dar "una" consideración primordial y no "la" consideración primordial lo cual indica que el denominado interés superior es una entre otras tantas consideraciones que deben tenerse en cuenta en la toma de decisiones relacionadas a los niños. Si bien el Comité de los Derechos del Niño ha declarado que el principio del interés superior del niño es "el principio rector-guía" de toda la CIDN ello no pasa de ser una afirmación entusiasta que contrasta con las reservas y aclaraciones que la jurisprudencia ha establecido en diferentes países. Más confusión añade el artículo 21 que establece que hay que darle a este principio "la" consideración "primordial" en los sistemas de adopción. Importante, principal, primordial son términos que están referidos a situaciones en donde debe definirse explícitamente el contexto de su aplicación. Hay por lo tanto, un amplio ámbito de interpretación y ello está lejos de ser una elucidación definitiva.

Otra dimensión importantísima de este artículo es la relacionada a lo que se define como 
"medidas" concernientes a los niños y si estas "medidas" alcanzan las omisiones. Está claro que en los redactores, este tema no tuvo la debida consideración. Pero éste es un punto central no sólo para la CIDN sino para todo el enfoque sobre derechos humanos. La doctrina convencional establece que las personas son responsables de los daños causados por los actos que efectivamente realizaron pero no por los daños causados por omisiones. Así planteado, este enfoque implicaría una responsabilidad humana muy restringida puesto que tratamos de cuestiones muy cruciales relacionadas a la vida y la muerte, la nutrición, la salud, la educación, etc. Hay omisiones ante hechos "previsibles" como los relacionados a la infancia y la adolescencia y también hay omisiones "intencionales". Por esta razón la distinción moral entre actos y omisiones ha sido severamente criticada y ha dado lugar al nacimiento del concepto de "obligación positiva" en relación a actos previsibles y prevenibles tanto a nivel individual como social (w). Volveré sobre este tema más adelante.

Y por último siguiendo nuestro análisis anterior del biopoder: este artículo de la CIDN que define el interés "superior" del niño y que habla de los "niños" en plural, podría haber significado el reconocimiento político del comienzo de una transferencia de poder a las nuevas generaciones mientras que en el caso del "mejor interés del niño", son los adultos en general los que deciden y definen "lo mejor" y lo hacen por supuesto, desde el poder.

En tercer lugar, está la cuestión de los derechos económicos y sociales. La CIDN reconoce en varios artículos (especialmente en su artículo 4) los derechos sociales aunque en relación a su financiamiento, establece que los Estados miembros deben cumplir con el "máximo de recursos posibles". Aclaremos que los derechos económicos operan como derechos "habilitantes" del resto de los derechos sociales: si no hay financiamiento, no hay derecho que pueda implementarse de un modo plenamente efectivo. En este punto, y en el contexto de la lucha Este-Oeste, hubo un fuerte enfrentamiento cuando se discutió la Convención: por un lado, los por entonces países que constituían la URSS que levantaban los argumentos que daban primacía a los derechos sociales y por otro lado, la oposición de EE.UU., que esgrimía la idea de que los derechos sociales no existen pues no hay nada que en principio pudiese ser demandable que no sea atribuible a un individuo. La fórmula finalmente adoptada "hasta el máximo" de los recursos disponibles no implica entonces un financiamiento conminatorio para los Estados Partes, para hacer efectivos los derechos sociales, particularmente en las épocas de recesión y crisis económicas en donde los más perjudicados resultan ser los niños/as y adolescentes. Algunos economistas, con realismo cruel, afirman que estos "derechos" son sólo "conditional oportunities" (25) (x), o sea, son sólo una posibilidad condicionada a la evolución de la economía y la "sacralidad" de las cuentas fiscales cuyo equilibrio por supuesto, está más allá de todo sacrificio impuesto a la infancia y la adolescencia. Y generalmente, como no cabe duda, suponer lo contrario, en un contexto de pugna sobre recursos escasos, no vale casi nunca aquello de "los niños primero" (y).

En cuarto lugar, está el punto de la adaptación de la legislación interna de cada uno de los países a los principios establecidos en la CIDN. Aquí la adaptación de la CIDN ha sido verdaderamente "invertida" en el sentido de que la mayoría de los países y particularmente los que tienen una estructura político-institucional federal la han verdaderamente "adaptado" a su legislación interna y no a la inversa como era lo originalmente propuesto. Lo que no ha podido ser adaptado a las condiciones de los que tienen el poder, finalmente no se ha "adaptado" o solamente se ha incluido lo que se considera "inofensivo"; esto es, lo que no tiene consecuencias reales. La institucionalidad judicial a su vez ha salido, salvo algunas excepciones, fortalecida como órgano protector de statu quo legal que criminaliza a los niños/as y adolescentes (z). Quiero traer como ejemplo el tema de bajar la edad de la imputabilidad de los "menores", que ha suscitado importantes y significativas discusiones en casi todos los países. Como lo afirmé anteriormente el discurso distorsionado que vincula infancia-adolescencia-seguridad ha tenido primacía en lo que constituye otra prueba contundente de cómo opera el biopoder con respecto a la represión de las nuevas generaciones. La imagen del "niño delincuente" generalmente y dolorosamente prima sobre la del "niño/a futuro" o niño/a esperanza" (aa). 
Las cuatro observaciones que hice me llevan a plantear en este campo el "estado de excepción", una de las categorías más profundas y originales formulada por Giorgio Agamben en donde analiza "la ambigüedad constitutiva del orden jurídico por el cual éste parece estar siempre al mismo tiempo afuera y adentro de sí mismo, a la vez vida y norma, hecho y derecho" (28 p.14). Y esta ambigüedad deja una zona vacía entre el derecho y la vida introduciendo en el caso del derecho positivo referido a la infancia, la posibilidad de la crueldad respecto a niños, niñas y adolescentes.

En el estado de excepción, el orden jurídico aparece vinculado a la guerra civil, a la insurrección y la resistencia. Serviría tanto para proteger como para anular la vida o para justificar tanto una democracia como un totalitarismo, lo que es su forma más frecuente. Igualmente, la oposición "dentro y fuera" del derecho que está implícita en las teorías del estado de excepción invalida lo que precisamente pretende explicar. En otras palabras, "si lo propio del estado de excepción es una suspensión (total o parcial) del ordenamiento jurídico: ¿Cómo puede tal suspensión estar comprendida en el orden legal?" (28 p.56).

Pero dejando de lado esa "vaguedad" más que sospechosa y que en muchos casos históricos sirvió para justificar los totalitarismos, es importante destacar la relación entre el estado de excepción y la necesidad. Como bien recuerda Agamben, históricamente existe una tradición que afirma que "la necesidad no tiene ley", lo cual puede significar cosas tan opuestas como "la necesidad no reconoce ley alguna" o "la necesidad crea su propia ley" (28 p.60). En este caso, se crea una situación de anomia de significados que en relación a la CIDN daría tanto para justificar por ejemplo, las demandas sociales emergentes respecto a la infancia y la adolescencia como también, su supresión vía una "necesidad" de equilibrio fiscal.

La situación planteada me lleva a afirmar que el refugio de las necesidades de la infancia y la adolescencia vía el orden jurídico son muy frágiles y están lejos de ser claras. En otras palabras: los derechos se reconocen en su condición de existencia pero se desconocen en su condición de ejercicio. Para colmo, un análisis del biopoder diría a este respecto que hay una potente polarización entre las fuerzas que se oponen a la ley y otras que la apoyan, lo que coloca el orden jurídico en una situación de casi perpetua tensión y ambigüedad. Esto puede instalar al derecho peligrosamente en una no relación con la vida o a su inverso que es lo más frecuente: la vida sin protección del derecho. Y esto es precisamente lo que frecuentemente sucede con la CIDN: tironeada desde su ambigüedad, entra y a la vez no entra en el orden jurídico; puede proteger o condenar con la máxima severidad. Ahora lo que sí debe quedar claro para una infancia y adolescencia que no pueden autorepresentarse, es lo que Agamben citando a Benjamin dice: "la tradición de los oprimidos nos enseña que el estado de excepción en el cual vivimos es la regla". Ahora si el estado de excepción es la regla aboliendo así la aplicación de la ley, ello borra dramáticamente la distinción entre violencia y derecho, entre ley y verdugo y por ende, la policía también se mueve en estado de excepción. Si esto fuese así, niños/as y adolescentes cuya constitución como categoría social reclama casualmente una consideración "especial" de la ley como lo establece la CIDN, ese estatus "especial" es un "estado de excepción" lo que en verdad los deja "fuera" de la ley y esto constituye un argumento contundente sobre su estado de indefensión (bb).

Aún con todas las objeciones realizadas, afirmo que la CIDN implica la posibilidad concreta de terminar con toda una cultura de la discrecionalidad de los padres, los funcionarios, el poder judicial y las ONGs (aunque lamentablemente la Convención no dice nada respecto del principal responsable, que es el sector privado). Igualmente, es claro que la pretensión de reducir los ámbitos de discrecionalidad de padres, maestros, funcionarios, ONGs y empresas es ampliar los ámbitos de la democracia aunque esto, por importante que sea, no descarta las dificultades de su implementación. En este sentido, coincido con García Méndez en que hay una fuerte correlación entre profundización de la democracia y reducción de la discrecionalidad puesto que, la discrecionalidad -como estado de excepción- históricamente ha demostrado que nunca funcionó para proteger a los grupos en los cuales se justificaba su intervención, pues así funciona el biopoder "soberano" tout court (29 p.28). 


\section{INFANCIA Y DERECHOS HUMANOS}

Complementariamente al punto anterior, no puedo dejar de referirme ahora a un enfoque reciente que coloca los derechos del niño/a y adolescentes como puntos prioritarios en la agenda por el cumplimiento de los derechos humanos. Más precisamente, en el contexto de los derechos económicos y sociales, se supone que la infancia debe ser un punto central en la lucha contra la pobreza y que por lo tanto, una estrategia que intente superar la misma debe comenzar por hacer efectivos los derechos de niños/as y adolescentes. Los derechos humanos deberían ser concebidos como un código moral que comenzaría a cumplirse en primer lugar con las jóvenes generaciones.

Puede observarse correlativamente que en las más recientes luchas por las identidades y el reconocimiento de las diferencias, hay un creciente proceso de "humanización" de los derechos particulares: todos los grupos sociales, entre ellos, las mujeres, los indígenas, las personas con capacidades diferentes, los "sin tierra", los "sin techo", etc., en la lucha por hacer "visibles sus derechos", intentan su "humanización" como derechos para, primero priorizarlos, segundo asegurar su inapelable cumplimiento y tercero universalizarlos. En ese contexto, niños/as y adolescentes también deben luchar para asegurarse "un lugar" en una agenda de derechos humanos paulatinamente tensionada y muy dinámica en lo que se refiere a los distintos contextos históricos desde donde una conflictividad social creciente los invoca. Habermas critica con razón esas diferencias en la lucha por los derechos que son exasperadas al límite y llama la atención sobre los grupos sociales que proceden "como monadas aisladas, que actúan interesadamente, que no hacen sino lanzar sus derechos subjetivos como armas los unos contra los otros" (cc). Aquí la infancia y la adolescencia corren con desventaja dada la imposibilidad de su autorepresentación como veremos más adelante.

Paralelamente, en el escenario internacional surgen sobre todo a partir de los años 70 los derechos humanos como una posibilidad de ordenamiento de un mundo globalizado en donde se piensa que deben existir algunos valores morales universales que sirvan como principios guías de la conducta humana, sea individual o colectiva y cuyo cumplimiento integral no pueda ser cuestionado. Los derechos humanos serían como un meta-derecho inapelable correspondiente a una moral "perfeccionista" pero esto está muy lejos de ser viable dada la naturaleza socialmente divergente de la cultura moderna.

Hay una manera neoliberal de plantear los derechos humanos que en este momento puede ser considerada hegemónica y que tiene que ver con el origen mismo de la Declaración Universal de los Derechos Humanos de 1948 que acordemos, fue elaborada sin la participación de la mayoría de los pueblos del mundo. Esta visión pone énfasis en el reconocimiento casi exclusivo de los derechos individuales; reconoce un derecho colectivo como la autodeterminación que fue cercenado en su origen por causa de los pueblos subyugados por el colonialismo europeo y ahora por el fundamentalismo para luchar contra el terrorismo; le otorga primacía a los derechos civiles y políticos sobre los derechos económicos, sociales y culturales y reconoce el derecho a la propiedad que fue durante muchos años, el único derecho económico inapelable (dd).

Esta tradición que continuamente se viene afianzando procede de una afirmación sobre los derechos humanos como derechos negativos: derechos destinados a amplificar la libertad individual contra el Estado, o los grupos o las clases sociales. No tienen como base ninguna idea de una naturaleza humana inapelable: los derechos humanos representan lo que es correcto y no lo que es bueno. Y como las ideas de bien implican un amplio espectro, un régimen que pretenda la universalidad de los derechos humanos debe ser compatible con un pluralismo moral. Es por esta razón que la virtud prudencial básica que se esgrime es aquella de la tolerancia sobre las diferencias en donde los derechos humanos terminan siendo según Gray (32 p.122159) un Modus Vivendi; o sea, una forma de compromisos precarios sujetos a un consenso que será determinado de acuerdo a circunstancias políticas y sociales concretas y no en abstracto. Como bien lo ha expresado Isaiah Berlin se trataría de seguir "el individualismo liberal que tiene como base una teoría minimalista del bien: define y prescribe lo negativo, es decir las 
restricciones e injusticias que hacen imposible la vida; al mismo tiempo, no prescribe ningún conjunto positivo de vidas buenas que se pueden llevar" a cabo (33 p.95) (ee). En esta visión, los derechos inculcan una "moral" en los seres humanos para ser "libre de" y no de ser "libre para". Como hay muy distintas concepciones del bien y de lo que se considera una vida buena se termina en un dramático relativismo cultural pero que, según los teóricos de las libertades negativas, este relativismo es la mejor coartada contra la tiranía.

Contra esta visión económica "ortodoxa" ha reaccionado Amartya Sen. Particularmente, en discusión contra el concepto de justicia de Rawls y las ideas centradas en el "liberismo" de Nozic, Sen ha levantado el enfoque de las capacidades que provee un sostén sustantivo para una caracterización más amplia de las libertades fundamentales y los derechos humanos y que toma en consideración la pobreza y sus consecuencias como el hambre, las enfermedades y la muerte que la misma conlleva. Sen argumenta correctamente, que la pobreza es una condición que restringe la libertad (freedom-restricting). Por ejemplo, si una persona vive desnutrida y en pobreza tiene una capacidad más que restringida para el ejercicio de las libertades básicas. En consecuencia, demandas mínimas relacionadas al salir de una situación de pobreza como nutrición adecuada, casa, vestuario y educación pueden ser conceptualizadas como derechos. Más aún, Sen avanza caracterizando los derechos humanos como "objetivos" del desarrollo argumentando que en un sistema ético sensible, los derechos humanos son el principal parámetro para evaluar el desarrollo (35-38) (ff).

Pero dejando de lado la "excepcionalidad" del enfoque de Sen, nos encontramos nuevamente en la Declaración Universal, con una ambigüedad particularmente en lo que respecta a los derechos sociales que es la misma que ya apuntamos en el caso de la CIDN. No es mi intención profundizar más este tema que requeriría entrar en un análisis mucho más detallado que el ya realizado. No obstante, debo afirmar que los derechos humanos tampoco escapan a una consideración biopolítica: su profundo contenido minimalista tiene como destino depositar y retener a las víctimas de la opresión en la nuda vida de la zoé y/o regular el despliegue de una ciudadanía basada en un individualismo sin contención en ninguna forma de heteronomía. Al individuo como fuera de la ley. Casualmente, el biopoder se legitima desligándose de todo lazo social, de toda ley común condenando a la mayoría de las personas a una economía restringida a una mera "conservatio vitae": la vida sacrificada sólo a su conservación.

Ahora, si hay algo positivo en los derechos humanos desde su instauración en los sucesos de 1789, es que han habilitado, aún con sus serias limitaciones normativas, el desarrollo y la conquista de innumerables derechos y defendido valerosamente millones de vidas humanas aunque la trayectoria de esas luchas está largamente incompleta. Como lo documenta Pablo Salbat, "la relevancia actual del tema de los derechos humanos encuentra sus orígenes, en la mayor parte de América Latina, en la década de los años setenta, y se relaciona histórico-políticamente, con la instalación de un conjunto de regímenes autoritarios que violan los derechos humanos de manera sistemática. Estos regímenes, en su mayoría gobiernos de las FFAA o sostenidos por ellas, se apoyaban ideológicamente en la doctrina de seguridad nacional, la cual obedecía a un esquema de relaciones políticas internacionales típico del período de la guerra fría entre bloques antagónicos" (39). Y nadie tendría condiciones de contradecir que la lucha por estos derechos desembocó en la conquista de la democracia y lo más importante, es que aún hoy constituyen la posibilidad más concreta de su profundización política.

Argumento que es necesaria una política de derechos humanos e igualmente una política para la CIDN que articule a ambos como instrumentos para la lucha política. Como ya sostuve, esa política debe basarse en luchas afirmativas ante la negatividad del mundo y en conformar una ciudadanía social que articule el amplio espectro de fuerzas que afirman la identidad y la diferencia (gg). Por lo tanto, esa política debe conciliar una esfera pública estatal y no estatal en un espacio público, cuya característica central sea la de estimular una lucha política transformadora. En este contexto, asevero que es un error separar lo humanitario implícito en los derechos humanos y lo político pues esto significaría aislar 
los derechos del hombre de los del ciudadano. Se equivocan las organizaciones humanitarias y particularmente las organizaciones supranacionales, al reducir la defensa de los derechos humanos a la vida nuda o zoé, a un minimalismo en la ayuda y protección sólo centrado en la sobrevivencia, abandonando el campo de la ciudadanía y la lucha política (hh).

En una humanidad exigida y violentada por una crisis sin precedentes, aparecen los derechos humanos como un espacio potencial aglutinante en donde es posible pensar una práctica política emancipatoria en el contexto histórico presente que aparece marcado por un generalizado escepticismo. Como afirma Pablo Salvat, los derechos humanos tienen una particularidad que es la de funcionar como idea reguladora a través de la cual se expresa -de distintas formas y en diferentes tiempos- la constante búsqueda del hombre de una mayor libertad y justicia y sobre todo, "como un posible foco articulador de un nuevo tipo de racionalidad integradora que coloca en su centro, una ética de la responsabilidad solidaria". Ahora es casualmente la solidaridad social la más combatida ya que, el mercado y el biopoder luchan por prescindir de ella puesto que la solidaridad social (ii) implica una dimensión profunda del ser orientado comunicacionalmente con "el otro" y por lo tanto, es un modo de coordinar la acción por medio de valores, normas y el empleo de un lenguaje que habilite el entendernos como ciudadanos. Habermas también ha destacado esta dimensión solidaria del bien y su vocación universal al afirmar que cuando interpretamos la justicia como lo igualmente bueno, el "bien" constituye un puente entre justicia y solidaridad (40, p.59). Y esto es crucial para la defensa de los derechos de la infancia y la adolescencia.

\section{EL ESTADO Y LOS NIÑOS/AS}

En una situación en donde la autonomía de una persona está en desarrollo y la heteronomía necesita ser constituida no como negación de la individualidad o como una situación opresiva sino como relación con "el otro" y en este caso me refiero a la sociedad, es indispensable la presencia de lo público. Si la infancia y la adolescencia son una categoría histórico-social, entonces se hace fundamental el poder configurador del Estado y su institucionalidad como garantes de una política pública respecto a los derechos de la infancia y la adolescencia.

Necesito acá hacer algunas precisiones sin entrar a desarrollar todas las argumentaciones que están involucradas en términos de la relación Estado-Sociedad Civil (41). Percibo que con una frecuencia sistemática, los analistas (sobre todo los filósofos europeos) argumentan una reiterada identificación del Estado como el origen del totalitarismo. Es cierto que la historia de Europa occidental ha estado asociada a las luchas por la libertad más que a la igualdad y en la última fase de su consolidación, al desgarramiento étnico asociado al emerger del Estado Nación (jj). Pero en este aspecto tomo otro rumbo, menos eurocéntrico, diferenciándome claramente de todos ellos.

Repasemos antes algunos elementos claves de esta discusión. En la mayoría de los análisis el centro de los cuestionamientos es el Estado como institucionalidad aglutinante y origen del totalitarismo y por lo tanto, el centro crucial de la opresión (kk). Es explicable que en esos exámenes después de las experiencias del Holocausto y el Gulag se identifique el peligro totalitario en el Estado particularmente en el "Estado-Partido". Además, debido a la presencia expansiva de la URSS, Europa occidental y sus teóricos, fueron siempre justificadamente desconfiados de una visión del aparato estatal asociado a la posibilidad de construir sociedades más isonómicas. Hasta ahí se entiende, y si la situación fuese así, ésta sería hasta justificable.

Pero desprendimientos de estos análisis resaltan una dualidad maniquea: sociedad civil "buena" y Estado "despótico y corrupto" (II). Como resultado de esos enfoques y de las políticas de "fortalecimiento" de la sociedad civil en el Este europeo y de la política del "empowerment" de las comunidades contra el Estado y la política, resultó un pavoroso y largamente documentado proceso de desmantelamiento de la institucionalidad pública acompañado de una privatización de servicios y de una flexibilización laboral que conllevó mayor desempleo y precariedad laboral $(\mathrm{mm})$. La correlación de fuerzas que emerge de 
esa situación, no cristaliza tampoco como se argumenta, en una sociedad civil "fortalecida" ni en la emergencia de una vigorosa esfera pública no estatal o en el surgimiento de nuevos movimientos y actores sociales con una subjetividad histórica, sino en un proceso de fraccionamiento y discontinuidad de las luchas sociales que pierden el carácter de construcción colectiva. En el final, estos desarrollos culminan en procesos de concentración del poder no ya en la "visibilidad" (controlable al menos como posibilidad) del "poder" de lo estatal sino en la "invisibilidad" de los intereses del poder biopolítico del mercado y de fuerzas que extraen su fortaleza en el ocultamiento de su configuración opresiva (nn).

Lo que no se entiende y no se puede justificar, es que no se centre el análisis sobre las crecientes desigualdades y la pobreza que afectan desproporcionadamente a niños/as y adolescentes e igualmente, a la ausencia de consideraciones relacionadas al poder expresado en el mercado y la economía. El Estado aparece como una institución no referenciada a la economía y autónomo de intereses que no sean los de una burocracia "insensible" o de partidos políticos concebidos como "máquinas" de poder. Incluso se Ilega a identificar a los funcionarios como "los enemigos" de los emergentes actores sociales "progresistas" (oo). Pareciera que, para muchos analistas europeos lo más "social" a lo que se puede llegar es al tema de los inmigrantes y por lo tanto, al multiculturalismo. De ahí las cuestiones relacionadas a las identidades sociales y las diferencias. Y la respuesta a esta situación, no pasa más que por la "tolerancia liberal". En esta visión, los filósofos "de izquierda" coinciden con los filósofos "de derecha", los que, en abierto ataque al Estado ponen en su lugar veladamente al verdadero poder, esto es el "mercado" y sus bases de dominación (44 p.97-113; 45 p.23-42; 46).

En tanto, en los países de "menor desarroIlo relativo" no puede explicarse ni entenderse el Estado como autónomo de la materialidad de la economía. El Estado no es una entidad abstracta sino que es un espacio de lucha en donde se puede configurar el sentido y la direccionalidad de las políticas públicas. Generalmente, en los países "más pobres" el Estado es "ocupado" por un gobierno circunstancial, determinado por intereses extraterritoriales y tiene en consecuencia, una institucionalidad muy frágil, sobre todo respecto a los intereses económicos asociados al mercado globalizado. El Estado entonces, ciertamente no representa el poder ni es el recinto del poder y las luchas sociales en este caso deben trascenderlo. Pero el Estado, sí puede ser origen de instancias a través de las cuales sea posible constituir una situación hegemónica que produzca un cambio sustantivo. El Estado puede configurar una posición positiva de separación del poder hegemónico -externo e interno- y al mismo tiempo y en determinadas circunstancias, representar un poder político autónomo. Aunque -seamos sinceros- también debe reconocerse que puede ser cierta la hipótesis contraria, especialmente cuando "ocupan" el Estado los partidos políticos autodenominados "progresistas" que terminan aceptando las prescripciones del poder para posibilitar hacer un país "gobernable". Pero en cualquiera de los casos, se trata de un espacio de lucha política (pp).

En el caso de la infancia y la adolescencia, las anteriores observaciones no son menores. Es claro que los derechos de niños, niñas y adolescentes no pueden recaer solamente en las organizaciones de la sociedad civil cuyo carácter insospechado en esa defensa está puesto en cuestión principalmente porque su existencia es casi imposible fuera de un subsidio público o privado. Y fundamentalmente por el análisis que hicimos de la microfísica del poder en este campo (qq). Tampoco estos derechos pueden quedar reducidos sólo a la familia, sobre todo al "familismo amoral" descrito por Banfield que implica la privatización de la infancia sometiéndola al ámbito "egoístico" de la familia y renunciar a su carácter social y político (rr). Pero principalmente, porque los derechos de los niños/as y adolescentes como relación social requieren de una política en el sentido de que su implementación será el resultado de luchas. Y el espacio que puede configurar esas luchas es público y su corolario concreto son políticas predominantemente aunque no exclusivamente estatales en donde el componente educativo tiene un rol crucial. Es cierto que el Estado abandonado a las determinaciones del poder económico y sus discursos distorsionados puede ser una causa de opresión de la infancia y la adolescencia. Esta situación, presentará un escenario para el desarrollo de luchas en 
favor de los derechos de niños/as y adolescentes frente al Estado y lo que éste representa. Pero es una enseñanza duramente aprendida en América Latina, que la "ausencia" frecuente del Estado en este campo ha demostrado ser, en las circunstancias histórico-sociales del presente, una de las principales causas del estado de indefensión de la infancia y la adolescencia. La primera consideración política que debe entenderse es que en la gran mayoría de los países de "menor desarrollo" la amenaza no es el totalitarismo sino la anarquía y que la primera condición para la defensa de los derechos es la presencia de una institucionalidad estatal fuerte con competencias para lograr la equidad.

Llegados a este punto, debemos ahora responder a otra cuestión sustantiva: dado el ámbito público de las luchas por los derechos de niños, niñas y adolescentes: ¿Quién "representa" la infancia y la adolescencia? Esto nos pone en relación con el tema de la democracia.

\section{INFANCIA Y DEMOCRACIA}

En términos de la teoría política tradicional, los atributos del hombre no tienen una distribución uniforme y se necesita de la política para construir igualdad. En un análisis del capitalismo que se base en una visión desde la biopolítica, la desigualdad es el punto de consideración central pues allí se encuentra el nudo que encubre el biopoder. Esto es más evidente en el caso de los niños y niñas que sobreviven en la zoé que no pueden autorepresentarse y por lo tanto, necesitan de la política para su ingreso al bios de la ciudadanía.

Para la infancia y la adolescencia, como se trata del desarrollo del proceso de autonomía en el contexto de una inserción emancipatoria en la heteronomía, la resolución del tema de la representación no es una cuestión fácil sino muy compleja.

Desde el comienzo, partimos de una limitación que es nuestra falta de memoria que empieza en la intensidad de la pubertad y que hace que olvidemos muy fácilmente la niñez y sus acontecimientos constitutivos asociados. Cuando contemplamos nuestra propia fotografía de pequeños nos cuesta reconocernos por ejemplo, en la foto de ese ser desnudo, o con el disfraz, o con ese rostro sonriente de ocasión; o cuando contemplamos la foto de nuestro primer documento de identidad. Esa es la muestra más triste de nuestra pérdida de memoria y el porqué nos cuesta tanto en la adultez representarnos ese período crucial de la vida.

Es entre otras cosas por esa pérdida de memoria, que una de las maneras más abruptas de los dispositivos ideológicos que inciden fuertemente en la indefensión de la infancia y la adolescencia es la expropiación de la posibilidad de su lenguaje, de manera que se produce una incomunicación intergeneracional en donde el único lenguaje legítimo es aquél de los adultos.

La interlocución generacional ilegítima pregunta para darse razón: los niños responden en el lenguaje "legítimo" de los adultos. Se produce una inversión que coloca al niño sólo como zoé e incompetente para el bios que lo habilita en el lenguaje. Los niños y niñas hablan pero lo hacen desde la aceptación de un "deber" impuesto por el adulto. Se produce una situación de heteronomía extrema en donde los adultos "adulteran" (ss). Lo descrito corresponde frecuentemente al ámbito de lo que se denomina "minoridad". El niño/a es un adulto en estado de reducción a una categoría "menor" o en su inverso, ser niño/a es no ser un adulto pleno. Esto introdujo tradicionalmente en la categoría infancia una asociación casi automática con la incapacidad.

Por otro lado, existe la visión que se presenta desde la pura autonomía de la persona en donde la subjetividad es concomitante al nacimiento del niño/a, o sea que todo niño/a trae en sí mismo los "genes" de su liberación (tt). Ser niño/a es estar destinado a la libertad pero como proyecto individual.

Concretando mis argumentos afirmo que se trata en democracia de construir un difícil equilibrio. No se puede renunciar al tiempo y la historia y pensar que la infancia y la adolescencia advienen a la vida fuera de todo contexto. Tampoco se podría pensar que la heteronomía siempre equivale a pura dominación y disciplinamiento. En el mismo sentido, no se podría analizar el proceso de individuación como un "absoluto" que ignore el "otro" y particularmente que corte la vinculación entre la subjetividad naciente 
de niños/as y adolescentes y la pertenencia a una familia y una sociedad. Como ha explicado Espósito, el ego sum se anuncia hacia "otro (al menos de ese otro en él que difiere de él mismo...), de modo que, puede decirse, todo ego sum es un ego cum" (48 p.14) y ese cum es lo que vincula, lo que relaciona y lo que junta.

Los derechos de niñas y niños y adolescentes en tanto que equilibrio tensional autonomía-heteronomía dependen entonces de la política para poder generar las condiciones de su ciudadanía. Pero este proceso es crecientemente complejo. En el caso de la familia, no se trata ni de una filiación solamente "obediente" ni tampoco, de una proyección narcísica de los padres sobre los hijos. Y recordemos aquí también una verdad elemental: la democracia comienza por la democratización misma de la familia (uu). En el caso educativo, el planteo no es la ya "clásica" visión "productivista" del sector educativo en donde la cuestión es educarse como proyecto individual para ser más "competitivo" y obtener éxito a través de "mejores" ingresos. Lejos de ello, aquí lo sustancial es observar una adecuada correlación entre la individualidad y la pertenencia social pero con una supremacía relativa de la heteronomía ya que la escuela es una institución por definición "socializadora" (vv). Y es bueno en este punto recordar las reflexiones acertadas de Marcel Gauchet en las que afirma que "la entrada en la vida es en todas sus etapas -desde la más precoz y cualquiera sea el apoyo recibido- un desafío tan temible, tan pleno de riesgos de inhibición y de fracaso, tan cargado de huellas imborrables". Y continúa afirmando sobre la dolorosa discontinuidad del crecer: "No hay acceso a la humanidad, no hay inclusión en la red ajustada de los símbolos que la representan y constituyen sin choque con la exterioridad violenta de una organización cuya coherencia nos precede, sin desesperación en cuanto a la posibilidad de nunca alcanzar ese lazo que nos envuelve y se nos escapa a la vez, sin paso por la angustia del desfase entre lo poco que comprendemos y la suma de lo que habría que dominar" (51 p.127).

Gomes da Costa considera acertadamente la relación infancia-democracia como el paso del "menor" al ciudadano (52 p.131) al que caracteriza como un proceso largamente incumplido. Los niños no son un sujeto colectivo y no han logrado un movimiento sobre sus necesidades ni luchado por sus derechos. Y como hablamos de democracia en su forma representativa, el problema básico de la infancia y la adolescencia es a la sazón que no pueden auto-representarse. Y sin poder social es difícil construir poder político.

La cuestión de los niños/as y adolescentes no es sólo un problema de identidad sino principalmente de igualdad y esto sería en principio lo más importante que debería garantizar una democracia. Ahora, en el caso de la infancia y la adolescencia tenemos un problema por partida doble ya que, de un lado tenemos la asimetría niño/a adulto y de otro, la que oprime igualmente a niños/as, adolescentes y adultos. Por lo tanto niñas/os y adolescentes en tanto que categoría social, están sujetos a una forma suprema de violencia simbólica: por ser "minorizados" y por ser pobres (ww).

Sin capacidad de auto-representarse, la defensa de los derechos de la infancia y la adolescencia queda en manos de los adultos. Se nos presentan aquí varios problemas no menores en esta representación "sin mandato". Denomino representación "Sin Mandato" a aquella que se produce cuando los adultos, las autoridades, los organismos de la sociedad civil y el mercado toman decisiones en nombre de la infancia y la adolescencia haciendo "suponer" una representación ni delegada ni demostrable. Como ha explicado muy bien Baratta (23 p.54) puede existir una cierta legitimidad en una representación sin mandato pero esto depende del vínculo comunicativo entre las partes y del deber de los adultos, "de aprender de los niños" y de "penetrar cuanto sea posible al interior de la perspectiva de los niños". Este ejercicio es una tarea que requiere márgenes de transparencia que raramente se logran. Lo anterior no quiere decir que sea un trabajo imposible y en todo caso, deberemos tener muy presente que desde una perspectiva biopolítica el mantener una infancia "irrepresentada", constituye un espacio temporal fundamental para la regulación de su vida como zoé y el punto central de su estado de indefensión.

Más lamentable es cuando se produce el síndrome de "Peter Pan", esto es, cuando los adultos tratan de "miniaturizarse" para parecerse y hablar el lenguaje de los niños/as. Operaciones como las siguientes suelen ser muy frecuentes: 
a. La manipulación política infantilizando la política como "juego" o estratagema para inducirlos a representar y emular las conductas de los adultos como forma de "deber".

b. La manipulación económica en donde el biopoder construye su subjetividad como consumidores. Aquí las formas son múltiples y van desde los dibujos animados, la publicidad y la imposición de modas hasta la "información" que se produce. Ahora, son formas verdaderamente paroxísticas de irresponsabilidad social aquellas usadas por las empresas de la industria del entretenimiento como sus "reality shows" (xx) Disney World y particularmente, Epcot Center, presentados como parques temáticos para exhibir la grandeza e infalibilidad del futuro del capitalismo. También, los "jueguitos" electrónicos y la industria del juguete bélico-agresivo, la Mc'minorización de la infancia y la adolescencia (55).

c. La manipulación social que los privatiza como categoría social reduciéndolos a "niño/a proyecto" de organismos tanto estatales como de la sociedad civil con "intervenciones" asistenciales "ejemplares" o "populismo" infantil presentando niños/as de un determinado proyecto como "víctimas" a los que, supuestamente "el" proyecto liberaría.

d. Las manipulaciones "pedagógicas" de diversas formas en donde niños/as son colocados en procesos de experimentación.

Ahora bien, recordemos que toda manipulación es una expresión de una situación de dominio y que el biopoder penetra en "la subjetividad" en evolución de la infancia y la adolescencia usando entre otras, algunas de las siguientes estrategias:

$\rightarrow$ La venta de productos baratos de consumo cultural: moda especialmente "casual" y deportiva, zapatillas, bebidas, comida rápida, música popular y películas (56). Esto tiene un gran impacto en adolescentes y jóvenes y es muy potente en la construcción de una homogeneización y de una rebeldía puramente epidérmica. Estos aspectos además, han funcionado como el integrador más exitoso de la globalización (57). $\rightarrow$ La "humanización" neo-liberal que opera mediante movimientos políticos liberales, socialdemócratas, innumerables ONGs financiadas por los países del norte y los bancos internacionales y cuyo centro conceptual es el "empoderamiento de la sociedad civil". Supuesta "transferencia" de poder a los pobres sólo a nivel local para que ellos "se ayuden a ellos mismos", se aparten de la política y desculpabilicen al Estado de sus obligaciones públicas. Y como se sabe, esta visión es especialmente activa en el caso de la infancia y la adolescencia (yy).

$\rightarrow$ Las drogas y sus diversas manifestaciones culturales políticamente inmovilizantes. El "piercing" y los tatuajes como autoagresiones en búsqueda de identidades "imborrables" o agresividad identitaria desde el cuerpo.

$\rightarrow$ La comunicación vía Internet que bajo la metáfora de la "red" oculta la desigualdad de los interlocutores y, bajo una creencia de "supercomunicación", en realidad termina dejando la certeza de la soledad y el aislamiento.

Obviamente que estas estrategias no son "condenables en sí" sino en su carácter manipulatorio. La sola enumeración de estos temas indica el amplio espectro en que el biopoder opera para regenerar constantemente su capacidad expoliativa. En este aspecto, el capitalismo muestra una creatividad y versatilidad admirables. Es por esta razón, que la dimensión educativa se hace estratégica y es donde más se necesita la presencia de un Estado que garantice el proyecto de una autonomía de la infancia y la adolescencia con pertenencia social y contribuya a configurar un contradiscurso público que supere las prácticas manipulatorias particularmente de los medios de comunicación masiva propagandísticos de determinados "estilos de vida".

En el caso de la asistencia social tanto pública como privada, ya es sabido que niños/as y adolescentes no pueden ser considerados como "objetos" de tratamiento y experimentación, ni tratados como pertenecientes al patrimonio de un proyecto o de un "benefactor". Entonces, la asistencia social también debe ser pensada como inscripta en un proyecto educativo que concilie como dije, una ayuda social consistente con una mayor autonomía, y creciente subjetividad con 
pertenencia social. Esto implicaría satisfacer al menos dos condiciones:

$\rightarrow$ La voz y el escuchar (artículo 12 de la CIDN), esto es, respetar su ingreso paulatino al lenguaje. Es interpretar la voz de los niños/as y adolescentes y su sentido. Una cuestión central es tomar el artículo 12 de la CIDN como principio general de la construcción de la subjetividad del niño/a teniendo en cuenta todas las dimensiones de su experiencia vital, intelectual y emotiva y no sólo sus "opiniones". Es fundamental la interpelación o interrogación y la heurística de la infancia en su profundo sentido interpretativo. Una heurística centrada en ellos, en la "eleidad". Nuevamente cito aquí las esclarecedoras palabras de Baratta: "sólo configurando el derecho del niño a ser escuchado, como deber de los adultos de escucharlo y aprender de él, es que el principio contenido en el artículo 12 se coloca como el principio central de la CIDN e indica un largo camino hacia el futuro de la relación entre niños y adultos. Pero este también es el camino hacia el futuro de la democracia" (23 p.54).

$\rightarrow$ La representación, esto es, la vinculación con la democracia. El niño es un sujeto social frágil que no puede autorepresentarse como ya lo traté ut supra. Y aún cuando esto debe ser materia de investigación, deseo añadir que hay situaciones de alta conflictividad que pueden identificarse como las peores formas opresivas como la de mantener a los niños/as cautivos de programas o víctimas de acciones en donde son objeto de cambio o de extorsión (zz). Se requiere en todos los ámbitos un proceso participativo cuidadoso y no demagógico. Ambas cuestiones, la voz y la representación, íntimamente ligadas merecen, repito, un estudio profundo desde lo cual se podrá entender mejor la relación crucial entre infancia y democracia.

La relación entre infancia y democracia no es entonces una cuestión resuelta: conocemos más los problemas que sus posibles soluciones. Lo central del estado de indefensión es que la biopolítica pretenderá siempre o sujetar los niños/as a una regulación opresiva de su vida y sobrevivencia o alejar a la infancia de la política y la democracia y disciplinarlos en las reglas del mercado como consumidores sumisos. Un programa de lucha por y con la infancia y la adolescencia deberá tener muy en cuenta esa situación de origen y sus dispositivos legitimadores para lanzar un programa verdaderamente emancipatorio. Un programa no fácil de definir, que deberá tener en cuenta las necesidades de formación de un ser con anclaje social y atento a la construcción de un futuro. Otra vez en palabras de Baratta ello requerirá pasar "de la política como administración del statu quo o como gestión eficiente de lo que hay, a la política como proyecto de sociedad". Y aquí los niños/as son la cuestión crucial.

\section{CONCLUSIÓN: LUCHAR POR LA INFANCIA ES DENUNCIAR EL MUNDO}

En tanto que política de regulación y control de la vida, la infancia y la adolescencia como relación social son una preocupación biopolítica central. La infancia y la adolescencia como nacimiento y comienzo de la vida implican que en ese campo se "juegue" el gran partido cuyo resultado tendrá un impacto directo sobre una política emancipatoria. Por lo pronto, el capitalismo conoce muy bien que allí es donde se "incuba" y se reproduce su poder y por ello realiza ingentes esfuerzos para controlar la construcción de la naciente subjetividad.

He recorrido el trayecto del discurso distorsivo y opresor que en su "candidez" solapada tiene un potencial demostradamente efectivo para captar incautos que creyendo trabajar por los niños/as y adolescentes terminan legitimando una relación de dominación de una crueldad feroz. En este sentido, la denuncia debe ser implacable. También he planteado las dificultades de un programa que constituyendo como "centro" la infancia y la adolescencia tenga en cuenta la historicidad de la sociedad y su futuro, en términos de instituciones claves como la familia y la escuela pero sobre todo, en los medios de comunicación masiva. Habrá que tener muy en cuenta que la "mediocracia" tiene un rostro bifronte: desde un lado "vende" publicidad y noticias, entretiene, distrae, defiende y legitima 
el biopoder ocultando sus estructuras opresivas y desde otro, se camufla en los momentos de crisis con el objeto de confundir, controlar y dirigir la protesta para someterla al poder del statu quo que en apariencia dice no representar. En el caso de la infancia y la adolescencia, la industria mediática construye lo imaginario y lo simbólico desde una perspectiva biopolítica con lo cual no sólo se pone al servicio del poder sino que lo integra en su mismo funcionamiento.

La cuestión de la relación de la infancia y la adolescencia y la democracia es un tema abierto por ambos lados: por las dificultades de auto representación de la infancia y la adolescencia y por la debilidad creciente de los sistemas de representación y organización democrática. Pero lo que no podemos obviar, es que tanto la infancia como los adultos en situación de pobreza son "cortados" por la misma relación social que los define mayoritariamente del lado de las víctimas. No hay niños/as y adolescentes "afuera" de una relación social, de lazos sociales que involucran tanto a ellos como a la generación adulta en una situación de opresión.

Luego he tratado la "centralidad" de los derechos y su "juricidad". El argumento principal es que del lado del "derecho", sobre todo de los derechos individuales en la modalidad liberal hegemónica que inspira al menos parte de la CIDN, estaremos sujetos a una casuística particular y limitados a un poder más que débil en la defensa concreta de los derechos de la infancia y la adolescencia como relación social. En las luchas sociales no hay "garantías" individuales conclusivas por encima de la política. Recordemos que en 1789, el título original de la declaración de derechos humanos decía: "Déclaration des droits de l'home et du citoyen" indicando que la idea del hombre era inseparable de la del ciudadano. Los derechos entonces deben ser conceptualizados como "sociales" y colocados en el ámbito de una lucha política que los "signifique" como una posibilidad concreta para una práctica emancipatoria. $Y$ recordemos siempre que las prácticas "adaptativas" de lo jurídico significan desde una visión biopolítica esencialmente eso: adaptarse al statu quo opresor. En todo caso, tanto en la defensa de los derechos en todas sus dimensiones, como en la cuestión del Estado o de la sociedad civil no propongo un abandono sino una resignificación de esos espacios pero como espacios para la lucha política. En este sentido, afirmo que la infancia y la adolescencia representan la positividad de una res gestae en donde se puede generar el quiebre y desarrollar en el tiempo una fuerza antagónica superadora.

A lo largo de este trabajo, he tratado de subvertir el lenguaje para develar las que considero principales estructuras de operación del biopoder sobre niños/as y adolescentes y también, analizar los procesos de producción de subjetividad que incluye a sus víctimas y victimarios esperando que este análisis, sea conducente a la construcción de un horizonte social y político que implique el nacimiento de un nuevo poder constitutivo liberador. Así afirmo que la infancia y la adolescencia son la ontogénesis de un proyecto humano largamente inconcluso pero al mismo tiempo, la posibilidad más importante para su realización.

Hechos estos planteamientos deseo insistir en una inversión lingüística básica: la cuestión de la infancia y la adolescencia no es una cuestión "menor" como argumenta el biopoder. Tal vez sea la cuestión "mayor" y crucial a resolver para un proyecto abierto al futuro que comience por anunciar la libertad desde el nacimiento, el principio y la iniciación de la vida. En este alumbramiento, la primera señal de que la vida ha llegado es el grito. $Y$ ante tanta crueldad con víctimas sin poder de autorepresentación y que se desarrollan en estado de indefensión, trabajar por y con ellas significa denunciar el mundo. 


\section{NOTAS FINALES}

a. En diciembre del año 2004 fui invitado por las autoridades de UNICEF a formar parte del panel de presentación del "Estado Mundial de la Infancia 2005" en la ciudad de México y cuyo sugestivo título era La Infancia Amenazada. A partir de ese evento decidí realizar las reflexiones que componen este trabajo. Deseo no "externalizarme" de las afirmaciones de estas notas: así, no me considero "el" sujeto emancipado que habla desde la libertad ni me siento inmune ante el fetichismo del consumo. No puedo engañar ni ocultar y presentarme como un "Yo" sujeto sano en una "sociedad enferma"; el "buen héroe" que batalla contra la "mala" sociedad. El capitalismo nos impregna a todos en diversas formas y el análisis que realizo no trata de ser un análisis "iluminado" que "se eleva" por sobre el combate sino simplemente, una modalidad -tal vez "menor"de inserción de la existencia en la lucha política. Y también una afirmación de que tanto el análisis como la reflexión son parte de la práctica cotidiana por alcanzar la dignidad.

b. Utilizo la palabra campo en el sentido de Pierre Bourdieu y como será precisada más adelante.

c. Infancia, niñez, niños, niñas y adolescentes serán términos utilizados indistintamente como todos los menores de 18 años como lo define la Convención Internacional de los Derechos del Niño.

d. Incluyo aquí la indigencia o lo que otros denominan pobreza absoluta.

e. Agamben habla del Homo Sacer (8 p.243,244) que "es precisamente aquél a quien cualquiera puede matar sin cometer homicidio". Los Ilamados pobres, indigentes y "desechables" entran en esta categoría ya que su muerte no tiene casi ninguna consecuencia jurídica. Así es la nuda vida, la vida "desnuda", a la que cualquiera puede anular impunemente y al mismo tiempo, ni siquiera puede ser "condenada" de acuerdo a los rituales establecidos.

f. Recordemos que en Rwanda en sólo 90 días fueron muertos más de 300 mil niños en 1990.

g. Muchos niños no mueren pero sufren otros padecimientos como quedar huérfanos, tener mutilaciones y padecer todo tipo de complicaciones psicosociales debido a la exposición directa a la violencia, al rapto, al desplazamiento, el abandono y la pérdida de sus seres queridos. Según la OIT, 12 millones de personas están bajo el régimen de trabajo "forzado" en el mundo, la mayoría de ellos niños y niñas. h. Este aspecto es de una efectividad impresionante. Por ejemplo, es altamente probable que las críticas como las de este trabajo serán tratadas como impiadosas o "desalmadas" y caracterizadas como carentes de objetividad. La crítica queda entonces "externalizada", los argumentos que quedan "de lado interior" legitimados y la visión del campo que impone el biopoder se hace aparentemente inviolable.

i. El poder mediático que determina en la mayoría de los casos las "prioridades" políticas de la democracia representativa hace crecientemente imposible a su vez, diferenciar entre tecnologías políticas y tecnologías para la construcción de la subjetividad. Ellas son siempre políticas.

j. Es impresionante el surgimiento de redes de solidaridad, proyectos y fundaciones solidarias y hasta los más audaces que anuncian el advenimiento de una "revolución" solidaria. Todas estas fundaciones tienen en general un sitio web en donde anuncian sus propósitos. Son muy ilustrativas aquellas en donde "la protección" que dan está arancelada. Por ejemplo: 1 niño U\$S 30 por mes; 1 niño HIV positivo U\$S35 por mes; una familia pobre U\$S40 (13). En los aspectos "conceptuales", se han producido muchas publicaciones sobre la "solidaridad", algunas de una insustancialidad supina como el libro de Pacho O`Donnell (14) u otras, que parecen sugerir como Marcos Aguinis (15), un verdadero despropósito como creer que: ¡la "salida" de Argentina está en el voluntariado!

k. El tema del voluntariado como práctica social ha sido bien estudiado desde hace mucho tiempo (recuérdense los análisis de Marcel Mauss sobre la economía del "don") y su fundamento "generoso" y altruista ha sido seriamente cuestionado. Véase Bourdieu, P. (10), capítulo 6 dedicado a la economía de los bienes simbólicos. Con respecto al voluntariado católico al que también muchos cuestionan su "entrega" y generosidad, consúltese en el mismo texto "La Risa de los Obispos", (10 p.186-198), en donde el autor se explaya sobre lo que denomina la economía de la "ofrenda".

I. Sugiero consultar aquí una obra señera y pionera que describe y explica el narcisismo en la cultura moderna. Christofer Lasch (16), sugiere que participar en una ONG donando tiempo libre para "purificar" la conciencia y sentirse "bien", es equivalente para muchos a concurrir a un gimnasio para mantener el cuerpo sano y bello. Allí, después del esfuerzo, uno también se siente "bien".

$\mathrm{m}$. Los temas de las relaciones de patrimonialismo y patronazgo en las ONGs así como, el ya 
"clásico" de las "primeras damas" y su asociación a la infancia los he tratado en el artículo "El abrazo" (6). Un caso "tipo" de despotismo ilustrado en el desarrollo de la política social fue el de Octavia Hill como presidenta de la National Charity Organization en Inglaterra. No menos importante, deseo destacar que hay frecuentes ejemplos de abuso flagrante de niños/as y adolescentes por parte de sus "benévolos" protectores.

n. Hay una "rentabilidad" de estos eventos que tienen como una escala en donde casi siempre tiene primacía la dis-capacidad pues es lo más convocante y en principio menos sospechoso. Aunque el marketing de estos espectáculos puede "convertir" en importante cualquier banalidad.

o. Los bancos internacionales y los fondos de inversión también utilizan frecuentemente la imagen de niños y niñas incentivando a los padres a efectuar "ahorros" en el presente para poder darles a "sus" hijos un futuro mejor. En ese contexto, colocan al niño "dentro de la familia" y ocultan en ese apelativo sus verdaderas "ganancias". El Banco Mundial usa en su publicidad programas de inmunización para niños o programas alimentarios en donde uno puede Ilegar a creer que es un verdadero "titán" en la lucha contra la pobreza y la defensa de los débiles. Lo que no se aclara es que, esos programas o se financian como créditos que los países devuelven con intereses más la correspondiente tasa de "riesgo país" o, son "premios" concesionales por haber realizado programas de ajuste económico aceptando con obediencia las "condicionalidades" que el Banco Mundial y el FMI imponen y que generalmente implican restricciones fiscales y monetarias con impactos socialmente regresivos.

p. Como ejemplo, Platt (17 p.22) comenta la lucha por la abolición del trabajo infantil entre los industriales de clase alta de Nueva York, que era vista como un medio para excluir a los comerciantes marginales y los trabajadores a domicilio, aumentando así la consolidación del poderío de sus negocios.

q. Esta expresión fue formulada por el Sr. James P. Grant, entonces Secretario Ejecutivo de UNICEF. EI Sr. Grant fue un luchador ejemplar y militante comprometido con la causa de los niños/as y adolescentes en el mundo y el principal artífice político de la Convención.

r. Me baso aquí en la filosofía de Levinas $(21,22)$ quien exige una destrucción de la ética basada en el subjetivismo individualista de la cultura moderna. Aquí el punto de partida será el reconocimiento de la alteridad absoluta del "otro". El "otro" en su dimensión de alteridad absoluta exige una ética de responsabilidad infinita. $Y$ esto significa que la filosofía tendrá que realizarse en la perspectiva del ethos de la persona y la sociedad. La experiencia humana se da por la posibilidad del ser humano de "ser para otro" en una relación ética que implica el cuestionamiento absoluto del "yo".

s. Es apropiado recordar aquí y tener presente desde el inicio, lo afirmado por Bobbio, citado por Baratta, (23 p.47) en el sentido de que los derechos de los niños están sujetos a una triple condicionalidad: 1) en forma indirecta, en el derecho de familia resultan automáticamente subordinados al derecho de los padres; 2) en forma condicional, cuando hay recursos económicos que deben ser puestos y no lo son inviabilizando el cumplimiento de los derechos; 3) la no existencia de derechos que sólo son reservados para los adultos.

t. Esta idea la tomo de Emilio García Méndez con quien he tenido la oportunidad de discutir ésta y otras tantas cuestiones relacionadas a la filosofía del derecho y particularmente de los derechos humanos.

u. Pensemos simplemente en la definición de cuándo comienza la vida, punto fundamental sobre el que no existió ni existe consenso. Otra cuestión no menor es la edad de los niños para ir a la guerra.

v. No se trata de un "error" de traducción. Las ONGs comprometidas con los derechos de la infancia y la adolescencia y bien intencionadas, en cierta medida han "impuesto" en sus valerosas luchas el concepto de "interés superior" pero lo que realmente corresponde es "el mejor interés del niño".

w. Es por esta razón que hay muchas declaraciones relacionadas al cumplimiento de los derechos que son fácilmente firmadas por las más altas autoridades pero que no son cumplidas puesto que las omisiones entre otras causas, no son tenidas seriamente en cuenta. Como ejemplo, véase la Declaración de San José de la VI Conferencia Iberoamericana de Ministras, Ministros y Altos Responsables de la Niñez y la Adolescencia (18 a 19 de octubre del 2004), en cuyos considerandos se utilizan verbos y expresiones como los siguientes: reiteramos, reafirmamos, reconocemos, resaltamos, reconocemos, preocupados, alarmados, concientes de la necesidad, etc.; los que hacen alusión y reclaman compromisos anteriores previamente asumidos que ni los signatarios firmantes en su momento cumplieron. Aquí vuelve lo del "Niño/a Sacer": ¿quién se hace responsable de sus muertes? ¿quién se compromete como obligación moral a responder por sus necesidades humanas más apremiantes? 
x. Debo aquí hacer una importantísima excepción con respecto al Premio Nobel de Economía Amartya Sen. Este economista ha realizado investigaciones pioneras demostrando las serias limitaciones que tiene la teoría económica ortodoxa para analizar las libertades fundamentales y los derechos humanos y ha realizado sustantivas contribuciones en el análisis de las relaciones entre ética y economía. Sen ha defendido la idea de que el proceso de globalización, incluyendo sus dimensiones económicas, debe estar sujeto a consideraciones morales, lo que implica tener en cuenta los principios éticos y legales que emergen de la idea de derechos humanos. Además, Sen ha sido siempre muy sensible a las necesidades de la infancia y la adolescencia y ha propuesto al indice de mortalidad infantil como el indicador más relevante para evaluar el desarrollo económico de un país. Es muy aconsejable en este punto, consultar el excelente trabajo de P. Vizard (26).

y. "No hay nada más nauseabundo que la procacidad con que los que han hecho del dinero la única razón de vivir agitan regularmente el fantasma de la crisis económica, y los ricos se revisten de austeridad para advertir a los pobres que van ser necesarios sacrificios para todos" (9 p.110).

z. Traigo de nuevo a colación los ejemplos dados en el trabajo de Platt (17 p.200), en este caso, en referencia a los tribunales de menores en los que concluye que " es imposible concebir el sistema de tribunales para menores como un organismo de rehabilitación y de igualdad social en una sociedad donde la mayoría de los jóvenes de la clase obrera y las minorías son encarrilados hasta puestos de trabajo de salario bajo o callejones sin salida, donde el racismo y el sexismo institucionales segmentan sistemáticamente a la gente en relaciones sociales antagónicas, y donde el sistema de justicia penal se utiliza descaradamente para socavar y reprimir los movimientos sociales progresistas".

aa. Emilio García Mendez (27) Ilama al sistema de "justicia" de menores argentino como la gestión de una "crueldad bondadosa" al presentar las sentencias de primera instancia condenando a cadena perpetua a personas menores de 18 años de edad (10 sentencias y 12 personas condenadas). Estas sentencias invocan que la Argentina "cumple" los principios establecidos en el artículo 37 párrafo a) de la CIDN incorporada a la Constitución Argentina en el artículo 22, en la medida que permite la excarcelación o en otras palabras acceder a la libertad condicional definida en el artículo 13 del Código Penal. Un verdadero artilugio jurídico inmoral. bb. En el momento de finalizar la escritura de este trabajo, el Congreso Nacional Argentino acaba de aprobar la ley largamente esperada de Protección de los Derechos de las Niñas, Niños y Adolescentes que adecua la legislación nacional a los principios, normas y procedimientos establecidos en la CIDN a su vez incorporada a la Constitución Nacional. Aún falta que el Poder Ejecutivo reglamente la nueva ley y lo que, la predominante práctica jurídica -asociada a visiones verdaderamente obsoletas- hará de ella. Puedo afirmar no obstante que, los efectos concretos de esta legislación serán complejos y múltiples y habrá ciertamente que esperar un período de "transición" para hacer una evaluación concreta. Ahora bien, la nueva ley no invalida en principio ninguno de los argumentos centrales de este trabajo, principalmente los relacionados al Estado de Excepción.

cc. La cita de Habermas está tomada de su exposición en la Academia Católica de Baviera el 19 de enero de 2004 en donde dialogó con el entonces cardenal Joseph Ratzinger sobre los fundamentos morales del Estado liberal basándose en argumentos centrados en la razón o en la fe. En otro orden y en conexión con el tema sobre el contenido de la conflictividad social moderna, puede afirmarse que uno de los "éxitos" más comprobables empíricamente del capitalismo es la transformación de la conflictividad "vertical" capital-trabajo en una conflictividad "horizontal" de luchas identitarias que en la mayoría de los casos, implican la defensa de derechos de pobres contra pobres (30).

dd. Con respecto a la Declaración Universal de los Derechos Humanos es crucial no olvidar que Churchil, Roosevelt y Stalin pretendían un acuerdo de seguridad colectiva para el período de postguerra. Los derechos humanos contaban muy poco en el orden de prioridades de las principales potencias, de modo que solo fueron mencionados una sola vez en el borrador de la propuesta de la Carta. América Latina desde 1938 en la Conferencia Interamericana ya había adoptado la "Declaración en Defensa de los Derechos Humanos" en su octava reunión en Lima, Perú. Sorprendentemente, esta Declaración contenía principios pioneros como el condenar la persecución racial y religiosa, en favor de los derechos de la mujer, y sobre el derecho de libre asociación de los trabajadores. Estos derechos más otros, fueron luego incorporados en la Declaración de Bogotá del 30 de abril de 1948 que fue la primera Declaración Internacional de Derechos Humanos. Los países latinoamericanos trataron de incluir los derechos humanos en la Declaración Universal originaria, lo que provocó reacciones de escepticismo en la delegación de 
EE.UU. y de franca hostilidad en las delegaciones de la Unión Soviética y de las naciones coloniales como Francia y Gran Bretaña. Fue recién en 1945, cuando se revelaron las fotos más cruentas del holocausto que causaron estupefacción en los países centrales, que se decidió incorporar en siete pasajes del documento original los derechos humanos y crear la Comisión de Derechos Humanos en el ámbito de la ONU. Recordemos también que el borrador de la Declaración fue encomendado a una Comisión presidida por Eleanor Roosevelt, esposa del Presidente de EE.UU. y que los comisionados de derechos humanos le pidieron la escritura del primer borrador al director del área de la ONU, el canadiense John Humprey. Cuando la Asamblea General de la ONU discutió el borrador de la Declaración se hizo un expreso reconocimiento a las contribuciones de los países latinoamericanos particularmente a Minerva Bernardino de la República Dominicana, a Guy Pérez Cisneros de Cuba, Jorge Carrera Andrade de Ecuador, Hernán Santa Cruz de Chile y a Eduardo Jiménez de Aréchaga de Uruguay. Finalmente recordemos que la Declaración Universal fue aprobada por unanimidad en la Asamblea General de la ONU el 10 de diciembre de 1948 con la abstención del bloque de la URSS, Arabia Saudita y África del Sur. En este tema, lo que más se necesita es no perder la memoria (31).

ee. Esta discusión tiene una larga trayectoria que comienza con un posicionamiento epistemológico sobre el ser, el conocer y el lenguaje (34).

ff. Deseo nuevamente introducir el tema de las "obligaciones positivas" que Sen enfatiza como responsabilidad ética ante las omisiones que como afirmé, en el caso de la CIDN es la puerta abierta para no cumplir con los derechos sociales. Aquí traigo a colación el muy apropiado ejemplo dado por Vizard (26 p.24,25), referido a los artículos 26-29 de la Carta de Derechos anexo a la Constitución de Sudáfrica de 1996 y que define un conjunto de derechos humanos esenciales para tener un adecuado nivel de vida. El carácter judiciable y legalmente demandable de esos derechos humanos ha sido puesto más allá de toda discusión por la Suprema Corte de ese país en una serie de fallos en los que, estableció que los mismos, son una obligación que el Estado debe cumplir. Aún cuando la misma Corte define que el Estado no está obligado a satisfacer esos derechos inmediatamente si no tiene los recursos económicos adecuados, también definió, que la falta de recursos sólo es justificable si el Estado demuestra fehacientemente que tiene una política y programas adecuados para asegurar el cumplimiento de esos derechos a largo del tiempo. gg. El concepto de multitud introducido por Negri y Hardt me parece que requiere mucha más investigación, sobre todo en lo que se refiere a la modalidad del espontaneísmo de luchas sociales que pareciera se coordinan por generación espontánea.

hh. Por ejemplo, el Alto Comisionado de las Naciones Unidas para los Refugiados establece en su estatuto que sus actividades no pueden tener un carácter político sino "únicamente humanitario y social". Aclaro que cuando me refiero a lo político no lo uso como concepto equivalente al político partidista.

ii. Deseo aclarar que estoy hablando de solidaridad "social" y no la "solidaridad" limitada a la familia, a los amigos, a la restringida a los alcances de un "proyecto" o a la "solidaridad" interesada del capital de la que hablé anteriormente.

jj. Desde 1913 han muerto en Europa como resultado de conflictos armados casi 70 millones de personas.

kk. La principal gestora de esta visión fue Hanna Arendt (42). Son muy sustantivas las reflexiones de Habermas (40): ¿Tiene futuro el Estado Nacional?

II. Esta concepción se originó principalmente en lo sucedido en Polonia y en los acontecimientos que determinaron la caída del Muro de Berlin.

mm. Las políticas de "empoderamiento" actúan sobre el principio de "ayudar a ayudarse", claro que, sin preguntarse por los causantes que originan que una persona necesite ayuda.

nn. Los peores crímenes contra la humanidad han dejado de ser exclusivamente de los Estados. Los cometen fuerzas paramilitares, carteles criminales y organizaciones económicas basadas en el tráfico de drogas, de armas y de personas.

oo. Uno podría entender que en el caso de Italia uno no tiene cómo perderse pues allí coincide el poder político como aparato, el poder económico particularmente como poder mediático y la corrupción como instrumento sistemático de acumulación económica y cooptación política. El totalitarismo allí pareciera ser una proximidad amenazante. Michelángelo Bovero (43) lo Ilama "cacocracia": la democracia en donde se eligen los peores. Pero esta situación histórica está lejos de ser universable. Otro caso más que comprensible es el de EE.UU. aunque allí el "modelo" del Patriot Act y su "justificación" es completamente distinto. 
pp. Una excepción en el pensamiento europeo es Boaventura de Souza Santos (47 p.17-22) quien plantea varias perplejidades de la modernidad, entre ellas, la pérdida del poder estatal como efecto de la globalización. Pero este autor se interroga porqué en lo cotidiano somos obsesivamente enfrentados con el Estado que ocupa las principales noticias en la TV, en los diarios y las radios. Y se pregunta: ¿será el Estado nacional una institución en vías de extinción o por el contrario, es ahora más central que nunca aún bajo la forma de una ambigua descentralización? ¿Será que el intervencionismo del Estado va asumir en los próximos años una forma de "intervencionismo no estatal"? ¿Será que el Estado va a crear una sociedad civil a su imagen y semejanza?

qq. Deseo y debo dejar muy en claro la distinción entre ONGs que representan los intereses del establishment económico de otras que representan los intereses humanos a nivel global y nacional. Su mandato por tanto, no es incrementar el poder de ningún grupo particular. Su acción política se basa en un Ilamado moral pues lo que está en juego es la vida misma. Representan una fuerza vital que transforma la lucha política en una cuestión de defensa y expansión de la vida en toda su generosidad.

rr. Deseo remitir en este punto a los mismos argumentos dados en la nota final (ss).

ss. Los adultos "producen" a su vez simulacros en donde por ejemplo hacen votar a los niños/as por sus derechos o los llevan a ocupar el recinto del parlamento para que "repitan" en esa "escenificación" montada el comportamiento de los adultos.

tt. Frecuentemente, cuando se habla de "sujetos de derechos" se asimila esa subjetividad a la del adulto y no una subjetividad que debería ser mediada y decodificada en sus propios parámetros. Por ejemplo; hay niños/as que desean enrolarse e ir a la guerra y están dispuestos a hacerlo pero esto no querría decir que esa "subjetividad" históricamente determinada por los adultos sea correcta.

uu. Muchas veces se asume que la familia es la primera línea protectora de los niños/as y adolescentes. Si bien la familia ha demostrado ser una institución social que pese a todos los procesos desestabilizadores aún sobrevive, ella se encuentra "en desorden" y algunas hipótesis sobre su futuro (dados los recientes desarrollos de la biotecnología) resultan por lo menos, desconcertantes (49).

vv. El proceso de formación más que una imposición sobre los niños debería presentarse como una articulación de los derechos individuales y sus responsabilidades sociales que se anclan en lo colectivo. En esto hay que insistir puesto que, esa relación individuo-sociedad hoy está resuelta ampliamente a favor del individuo y sus derechos. En este contexto y sobre la participación de los niños/as, concuerdo con Tenti Fanfani (50 p.485) que en una educación democrática, no es sólo importante aprender las reglas de la República, como estudiar la Constitución, sino principalmente en construir una escuela democrática "donde los niños no sólo aprenden conceptos sino que viven experiencias: votan, toman decisiones en conjunto, se hacen responsables de las consecuencias de las decisiones que toman, argumentan, debaten, evalúan, controlan". La experiencia de "Escuela Nueva" en Colombia puede ser un buen ejemplo. Y esto, no como "escenificación" como se aclara en la nota final (II) y otras partes de este trabajo.

ww. Dice Pierre Bourdieu (53 p.112) "Habrá que movilizar, sin duda, cada vez más justificaciones y recursos técnicos y racionales para dominar, y los dominados tendrán que utilizar cada vez más la razón y los argumentos para defenderse de formas cada vez más racionalizadas de dominación".

xx. El "encerrar personas" y provocar una reacción de sus conductas con fines de espectáculo en donde en forma de "juego" se promueve la eliminación y supresión del "otro" mediante el engaño, la competencia despiadada al límite de la traición "justificable" en la idea de vencer a cualquier costo, puede ser tomada como la representación escenificada de un zoológico. De una zoé más próxima a un estado de animalidad (54).

yy. Afirma acertadamente James Petras (58 p.105) que las "ONGs no son en realidad no gubernamentales. Sus fondos provienen de los gobiernos extranjeros y trabajan como subcontratistas privados de los gobiernos nacionales. Con frecuencia, colaboran abiertamente con las agencias gubernamentales nacionales y extranjeras. Estas subcontrataciones sirven para erosionar las formas tradicionales del servicio público, que implicaban la asignación fija de trabajadores a los servicios. Ahora los profesionales son contratados en precario, temporalmente o por obra. Las ONGs no tienen capacidad para ofrecer los amplios programas a largo plazo que el Estado de Bienestar puede proporcionar. En su lugar, las ONGs dispensan servicios limitados a los que sólo acceden pequeños grupos o comunidades. Y lo que es más importante: no son responsables ante las personas que trabajan, sino ante sus donantes extranjeros. En este sentido, las ONGs minan las bases de la democracia, pues sustraen el control de los programas sociales de las manos de las poblaciones locales y de sus representantes electos, creando 
una dependencia ante funcionarios extranjeros no elegidos y ante sus responsables nombrados localmente".

zz. Uno de los casos que debe ser analizado con sumo cuidado es la situación que se produce cuando hay conflictos salariales en el campo educativo. Aquí frecuentemente, bajo el discurso de defender los intereses de la escuela y los derechos de los niños se los mantiene como cautivos en una forma de chantaje social. Bajo un seudo progresismo se pretende hacer creer que enseñar, esto es, el complejo proceso de iniciar a los chicos en el lenguaje de la ciudadanía, es un problema solamente salarial. Aquí también hay una situación clara de biopoder sobre la infancia que se expresa en las burocracias sindicales y sectoriales a quienes les cabe las palabras de Baruch Spinoza: "creyendo luchar por su liberación escogen el camino de su esclavitud". Tratan a la infancia como rehenes y moneda de cambio en conflictos salariales y/o de rivalidades internas en donde la "intransigencia" es un eufemismo para captar mayores adeptos/contribuyentes de estructuras burocráticas corruptas. También los que "viven" de la infancia en los Institutos de Internación y que se niegan a des-institucionalizar a los niños/as y adolescentes bajo la excusa de que perderían el trabajo. Nos recuerdan tristemente la anécdota del enterrador que decía: "yo no le deseo el mal a nadie... pero tengo que sobrevivir".

\section{REFERENCIAS BIBLIOGRÁFICAS}

1. Foucault M. Historia de la Sexualidad. Buenos Aires: Siglo XXI; 1991. vol 1.

2. Boltvinik J. Comercio Exterior. Mayo 2003;53(5):404-409.

3. Boltvinik J. Comercio Exterior. Junio 2003;53(6):504-508.

4. Minujin A, Delamónica E. Children Living in Poverty. A review of child poverty definitions, measurements and policies. New York: UNICEFNew School Paper; 2005.

5. Boltvinik J, Damián A. La Pobreza en México y el Mundo. México: Siglo XXI Editores; 2004.

6. Bustelo ES. De Otra Manera. Ensayos sobre Política Social y Equidad. Rosario: Homo Sapiens; 2000.
7. Minujin A, Delamonica E. ¡Mind the Gap! Widening Child Mortality Disparities. Journal of Human Development. Nov 2004;4(3):397-481.

8. Agamben G. Homo Sacer. El Poder Soberano y la Nuda Vida. Valencia: Pre-Textos; 2003.

9. Agamben G. Medios Sin Fin. Valencia: PreTextos; 2001.

10. Bourdieu P. Razones Prácticas. Barcelona: Anagrama; 1997.

11. Foucault M. Vigilar y Castigar. México: Siglo XXI; 1985.

12. Revista Noticias. Buenos Aires. 2002;XXI(1339):6.

13. Help a Child to Escape the Tidal Wave of Poverty [en línea]. 2003 [fecha de acceso 22 de mayo de 2005] URL disponible en: http://www.worldvision.org. 
14. O'Donnell P. El Prójimo. La revolución de los solidarios. Buenos Aires: Planeta; 2001.

15. Aguinis M. El Atroz Encanto de Ser Argentinos. Buenos Aires: Planeta; 2001.

16. Lasch Ch. La Cultura del Narcisismo. Santiago de Chile: Editorial Andrés Bello; 1999.

17. Platt AM. Los "Salvadores del Niño" o la Invención de la Delicuencia. México: Siglo XXI; 2001.

18. Gomes da Costa AC. Pedagogía y Justicia. En: García Méndez E, Bellof $M$, compiladores. Infancia, Ley y Democracia en América Latina. Buenos Aires: Ediciones Depalma; 1998.

19. Himmelfard G. Poverty and Compassion. New York: Vintage Books; 1992. p. 79-122.

20. Bauman Z. Ética Posmoderna. Buenos Aires: Siglo XXI Editores; 2004.

21. Lévinas E. Totalidad e Infinito. Salamanca: Ediciones Sígueme; 2002.

22. Lévinas E. Entre Nosotros. Valencia: PreTextos; 2001.

23. Baratta A. Infancia y Democracia. En: García Méndez E, Bellof M, compiladores. Infancia, Ley y Democracia en América Latina. Buenos Aires: Editorial Depalma; 1998.

24. Alston $\mathrm{P}$, Gilmour-Walsh B. El Interés Superior del Niño. Buenos Aires: UNICEFArgentina; 2002.

25. Barbalet JM. Citizenship: Rights, Struggle, and Class Inequality. Minneápolis: University of Minnesota Press; 1988.

26. Vizard P. The Contributions of Professor Amartya Sen in the Field of Human Rights. Centre for the Analysis of Social Exclusion. London: London School of Economics; 2005. Case paper 91.

27. García Méndez E. Sentencias de Reclusión Perpetua y Prisión Perpetua a Personas Menores de 18 años de Edad en la República Argentina (1997-2003). Buenos Aires: Colegio de Abogados de la Capital Federal, UNICEF; 2003.

28. Agamben G. Estado de Excepción. Buenos Aires: Adriana Hidalgo Editora; 2003.

29. García Méndez E. Infancia, Ley y Democracia: una cuestión de Justicia. En: García
Méndez E, Bellof M, compiladores. Infancia, Ley y Democracia en América Latina. Buenos Aires: Ediciones Depalma; 1998.

30. Brenner R. Turbulencias en la Economía Mundial. Santiago: LOM Ediciones; 1999.

31. Glendon MA. El Crisol Olvidado: Influencia Latinoamericana en la Idea de los Derechos Humanos Universales. Revista Criterio. Mayo 2004;(2293):239-244.

32. Gray J. Las Dos Caras del Liberalismo. Barcelona: Editorial Paidós; 2001.

33. Ignatieff M. Los Derechos Humanos como Política e Idolatría. Barcelona: Paidós; 2003.

34. Rorty R. Objectivity, Relativism and Truth. Cambridge: Cambridge University Press Philosophical Cambridge; 1991. Papers vol I.

35. Sen A. Rationality and Freedom. London: Belknap Press; 2002.

36. Sen A. Development as Freedom. Oxford: Oxford University Press; 1999.

37. Sen A. Inquality Re-examined. Oxford: Clarendom Press; 1992.

38. Sen A. Rights and Agency. Philosophy and Public Affairs. 1982;11(1):325-345.

39. Salvat P. Derechos Humanos. En: Conceptos Fundamentales. Santiago: Edición de la Universidad Silva H; 2005.

40. Habermas J. La Inclusión del Otro. Estudios de Teoría Política. Barcelona: Paidós; 1999.

41. Cohen JL, Arato A. Sociedad Civil y Teoría Política. México DF: Fondo de Cultura Económica; 2000.

42. Arent $\mathrm{H}$. Los Orígenes del Totalitarismo. Madrid: Taurus; 1980.

43. Bovero $M$, Ferrajoli L. Teoría de la Democracia. Dos perspectivas comparadas. México DF: Instituto Federal Electoral; 2001.

44. Hardt M, Negri A. Imperio. Buenos Aires: Editorial Paidós; 2002.

45. Negri A. Guías. Cinco Lecciones en torno a Imperio. Buenos Aires: Paidós; 2004.

46. Virno P. Gramática de la Multitud. Buenos Aires: Ediciones Colihue; 2003. 
47. De Souza Santos B. Pela Mao de Alice. O Social e o Político na Pós-modernidade. San Pablo: Cortez Editora; 2005.

48. Nancy JL. Coloquium. En: Espósito R. Communitas. Origen y Destino de la Comunidad. Buenos Aires: Amorrortu Editores; 2003.

49. Roudinesco E. La familia en Desorden. Buenos Aires: Fondo de Cultura Económica; 2004.

50. Tenti Fanfani E. La Cuestión Social Contemporánea y la Educación Básica. Revista Criterio. Septiembre 2004;(2297):481-485.

51. Gauchet M. La Democracia contra sí misma. Rosario: Homo Sapiens Ediciones; 2004.

52. Gomes da Costa AC. Del Menor al Ciudadano Niño y Ciudadano Adolescente. En: García Méndez E, Carranza E, editores. Buenos Aires: Del Revés al Derecho, Galerna; 1992.
53. Bourdieu P. Meditaciones Pascalianas. España: Anagrama; 1999.

54. Bancel N, Blanchard P, Boëtsch G, Deroo E, Lemanaire S. Zoos Humains. Au Temps des Exhibitions Humaines. París: Éditions La Découverte; 2002.

55. O'Neil J. Mc Utopia: Eating Time. En: Kumar K, Bann S, editors. Utopias and the Millennium. London: Reaktion Books; 1993.

56. Klein N. No Logo: el poder de las marcas. Buenos Aires: Paidós; 2001.

57. Man M. La globalización y el 11 de septiembre. New Left Review. Enero-Febrero 2002;(12):5-26.

58. Petras J. La Izquierda Contraataca. Madrid: Ediciones Akal; 2000.

Recibido el 27 de septiembre de 2005

Versión final presentada el 20 de octubre de 2005

Aprobado el 2 de noviembre de 2005 